\title{
Measurement and Prediction of Phase Transformation Kinetics in a Nuclear Steel During Rapid Thermal Cycles
}

\author{
G. OBASI, E.J. PICKERING, A.N. VASILEIOU, Y.L. SUN, D. RATHOD, M. PREUSS, \\ J.A. FRANCIS, and M.C. SMITH
}

\begin{abstract}
Accurate prediction of the residual stress distributions in steel welds can only be achieved if consideration is given to solid-state phase transformation behavior. In this work, we assess the ability of a model for reaction kinetics to predict the phase transformations, and corresponding evolution of volumetric strain, in a nuclear pressure vessel steel when subjected to rapid weld-like thermal cycles. The cases under consideration involved the rapid heating of SA508 steel to a temperature of either $900{ }^{\circ} \mathrm{C}$ or $1200{ }^{\circ} \mathrm{C}$ for a period of 10 seconds, and subsequent cooling of the material to room temperature at rates between 0.1 and $100{ }^{\circ} \mathrm{C} \mathrm{s}^{-1}$. Predictions for the microconstituent proportions and transformation temperatures for each thermal cycle are compared to those measured through a combination of dilatometry, optical and electron microscopy, and synchrotron X-ray diffraction. In general, there was good agreement between measured and predicted transformation start temperatures and microconstituent fractions for cooling rates relevant to welding $\left(\geq 10^{\circ} \mathrm{C} \mathrm{s}^{-1}\right)$. Even in the cases in which discrepancies were found for start temperatures, examination of the corresponding dilatation curves showed a good match between predicted and experimental transformation strain evolution. This is a very positive result in terms of residual stress prediction in welds. At slower cooling rates, significant discrepancies arose owing to the model's incapacity to predict Widmanstätten ferrite or retained austenite, and its failure to account for the effects of carbon redistribution during transformations involving diffusion. Although not relevant to welding, improvements to the model to rectify these issues would be beneficial in terms of its wider predictive capabilities.
\end{abstract}

https://doi.org/10.1007/s11661-018-05102-y

(C) The Author(s) 2019

\section{INTRODUCTION}

To ensure the safe operation of nuclear power plants, it is critically important that the large pressure vessels used in their construction are of the highest integrity. To manufacture such components, for example reactor pressure vessels or steam generators, it is usual for a number of forged sections to be joined together by welding. This is somewhat problematic for design engineers, since although they may be confident of the mechanical properties of bulk forgings, the characteristics of the connecting welds are often less well-understood. In engineering applications, it is often

G. OBASI, E.J. PICKERING, and M. PREUSS are with the School of Materials, University of Manchester, Oxford Road, Manchester, M13 9PL, UK. Contact e-mail: ed.pickering@manchester.ac.uk A.N. VASILEIOU, Y.L. SUN, D. RATHOD, J.A. FRANCIS, and M.C. SMITH are with the School of Mechanical, Aerospace and Civil Engineering, University of Manchester, Oxford Road, Manchester, M13 9PL, UK.

Manuscript submitted July 5, 2018.

Article published online February 4, 2019 found that welds can be a source of structural weakness and failure, and hence there is a great deal of interest in assessing their integrities in nuclear pressure vessels.

Residual stresses are known to exacerbate weld failures when they occur through fast fracture ${ }^{[1,2]}$ fatigue,$^{[3,4]}$ creep $^{[5,6]}$ and stress corrosion cracking. ${ }^{[7]}$ Since experimental evaluation of the stress fields present in large pressure-vessel welds is usually not feasible, advanced numerical techniques are required to predict their distribution. This is an especially formidable task for ferritic steels, because the stresses arising from welding depend not only on the differential thermal contractions experienced across the weld area during cooling, but also on the particular phase transformations that occur when austenite decomposes upon cooling. ${ }^{[8-10]}$

The strain associated with the austenite-to-ferrite transition is a volume expansion. Its effect on a weld's residual stress field will depend on the temperature at which it occurs, and can be accounted for to a reasonable extent if the phase evolution behavior with temperature is known. 
However, there are several complicated effects that are influenced by the different microconstituents (e.g., bainite, martensite) that can be formed when austenite decomposes on cooling, and each of these microconstituents possesses its own characteristic transformation behavior and mechanical properties. Not only will each constituent yield at a different stress, thereby redistributing residual stresses to differing degrees, but complex phenomena can also result in strains being distributed non-uniformly across different microconstituents. For instance, the formation of a harder microstructure (martensite or bainite) in a softer phase (austenite) of a different density can lead to strain concentrations in particular regions of material (so-called Greenwood-Johnson plasticity ${ }^{[1,12]}$ ), and the selection of particular crystallographic variants of martensite can also influence the total strain. ${ }^{[9,13]}$ Both of these effects fall into the category of strains referred to as being due to transformation plasticity, which has attracted continuous research effort to understand and model. ${ }^{[14-17]}$ Even more complexity is added when it is recognized that many of the physical processes influencing stress evolution are coupled together ${ }^{[8]}$ - for instance, the martensite start temperature is a function of stress state, but the stress state is itself a function of martensite fraction and crystallography. Altogether, the total macroscopic strain, $\varepsilon_{\text {Tot }}$, can be divided into the following terms, all of which need to be understood in terms of their evolution with temperature during cooling, while also accounting for their interdependency ${ }^{[8]}$ :

$$
\varepsilon_{\mathrm{Tot}}=\varepsilon_{\mathrm{e}}+\varepsilon_{\mathrm{p}}+\varepsilon_{\mathrm{th}}+\varepsilon_{\mathrm{tr}}+\varepsilon_{\mathrm{trp}}
$$

where $\varepsilon_{\mathrm{e}}$ is the elastic strain generated by the current stress state, $\varepsilon_{\mathrm{p}}$ is the classical plastic strain, $\varepsilon_{\text {th }}$ is the strain due to thermal contraction or expansion, $\varepsilon_{\mathrm{tr}}$ is the volume change due to the decomposition of austenite, and $\varepsilon_{\operatorname{trp}}$ is the strain due to transformation plasticity.

Without a detailed knowledge of the phase transformation behavior of a steel that is subject to rapid thermal cycles, it is impossible to evaluate the terms in equation 1 above and predict the residual stress field across a weld accurately. Furthermore, it is also difficult to assess whether the magnitude of residual stress present is likely to lead to material failure or not. Harder microstructures like martensite tend to be more susceptible to crack propagation than softer structures like pearlite, so it is also necessary to have knowledge of the final microstructure of a weld in order to assess its structural integrity. A number of investigators have implemented some form of phase transformation prediction into finite element models for of welding residual stresses. $^{[10,18-20]}$

In this work, we examine the transformation behavior of SA508 Grade 3, ${ }^{[21]}$ the world's most common pressure-vessel steel. Continuous-cooling transformation (CCT) diagrams have been measured for this alloy in the past, ${ }^{[2]}$ but none have considered the unique thermal cycles associated with welding. We use a combination of dilatometry, synchrotron X-ray diffraction (SXRD), optical microscopy, scanning electron microscopy (SEM), transmission electron microscopy
(TEM), and Nano secondary ion mass spectrometry (NanoSIMS) to characterize the phase transformation behavior of SA508 Grade 3 during two thermal cycles: one simulating the coarse-grain heat-affected zone (HAZ) of a weld, the other the fine-grained HAZ. The experimental results are then compared to predictions made by an analytical model for phase transformations in low alloy steels implemented in the Abaqus finite element package using FORTRAN User subroutines. For the first time, we compare the full transformation evolution profiles obtained from dilatometry with those predicted using a kinetic model, across a range of cooling rates.

\section{EXPERIMENTAL}

The composition of the SA508 Grade 3 Class 1 material used for this study is shown in Table I.

Since the material was taken from a large forging (cast as a large ingot), during sample machining it was desirable to avoid the macrosegregation defects that are commonly found in such products. ${ }^{[23,24]}$ This was achieved by macroetching the sample in a 5 pct nitric acid solution (aqueous), and avoiding the enriched material found in A-segregate channels, Figure 1. Cylindrical specimens suitable for dilatometry measuring 4

Table I. Composition of the SA508 Grade 3 Steel Used, in Weight Percent

\begin{tabular}{lllllll}
\hline $\mathrm{C}$ & $\mathrm{Mn}$ & $\mathrm{Ni}$ & $\mathrm{Mo}$ & $\mathrm{Si}$ & $\mathrm{Cr}$ & $\mathrm{Cu}$ \\
0.16 & 1.43 & 0.77 & 0.52 & 0.27 & 0.23 & 0.04 \\
$\mathrm{Al}$ & $\mathrm{N}$ & $\mathrm{V}$ & $\mathrm{Ti}$ & $\mathrm{P}$ & $\mathrm{S}$ & \\
0.020 & 0.010 & 0.003 & 0.003 & 0.005 & 0.002 & \\
\hline
\end{tabular}

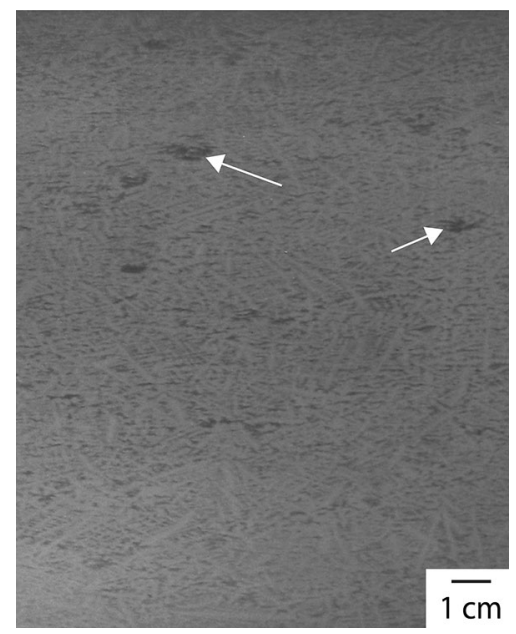

Fig. 1-Macroetching was used to reveal the locations of macrosegregation defects in the forged material, as indicated. These are the results of A-segregation, see Refs. [23], [24] for further details. The finer features are the result of microsegregation (associated with dendrite arms). 
$\mathrm{mm}$ in diameter and $10 \mathrm{~mm}$ in length were prepared by electrical discharge machining.

Dilatometry experiments were performed using a BAHR DIL-805 pushrod dilatometer. The sample was heated by an induction coil and temperature was measured by a thermocouple spot-welded onto its surface at its center. Two sets of heat treatments, shown in Table II, were applied in order to mimic the thermal cycles experienced in the fine-grained HAZ (FGHAZ) and coarse-grain HAZ (CGHAZ). Samples were heat treated under vacuum, apart from quenching steps in which He gas was used to cool the material. Microconstituent percentages (e.g., percentage bainite) were found by extrapolating the strain curves for the untransformed $\left(\varepsilon_{\gamma}\right)$ and fully transformed cases $\left(\varepsilon_{\alpha}\right)$ as shown in Figure 2(a) and using the following lever rule type expression:

$$
\text { Pct transformed }=100 \times \frac{\varepsilon-\varepsilon_{\gamma}}{\varepsilon_{\alpha}-\varepsilon_{\gamma}} .
$$

Microconstituent percentages were evaluated at the start temperatures for subsequent transformations (e.g., the percentage of allotriomorphic ferrite evaluated was taken as the percentage transformed at the onset of the bainite/Widmanstätten ferrite transformation). Transformation start temperatures were determined in two ways. (i) In cases where a well-defined portion of linear behavior preceded the transformation (i.e., where no transformation was occurring) the start temperatures were determined by the consistent linear offset method used by Yang and Bhadeshia ${ }^{[25]}$ as shown in Figure 2(b). However, in a modification to the approach, the offset used attempted to account for the high temperatures of transformation generally observed in SA508 Grade 3. Yang and Bhadeshia used the offset corresponding to 1 pct transformation to martensite at room temperature, whereas we used the offset corresponding to 1 pct ferrite formation at $600{ }^{\circ} \mathrm{C}$. This offset was found using the same calculation tools as Yang and Bhadeshia, ${ }^{[25]}$ but utilizing linear thermal expansion coefficients of $1.76 \times 10^{-5}$ for ferrite and $2.45 \times 10^{-5}$ for austenite ${ }^{[26]}$. (ii) In cases in which no linear portion of the curve preceded the transformation event, Figure 2(c), the start temperatures were evaluated by finding the point of inflexion in the data see Figure 2(d) inset. The uncertainty associated with measuring start temperatures by these methods was estimated by evaluating the same transitions using both methods. It was found that the second derivative method delivered a higher transformation temperature than the offset method, but the maximum difference was only $25{ }^{\circ} \mathrm{C}$. This $25^{\circ} \mathrm{C}$ uncertainty in transformation temperature introduced uncertainty in microconstituent percentages when more than one microconstituent was present. This was estimated for each sample by determining the variation in percentage that a $25^{\circ} \mathrm{C}$ variation in temperature would incur and adding it to the uncertainty in the retained austenite measurement. In cases where only one microconstituent was deemed to be present, the uncertainty 


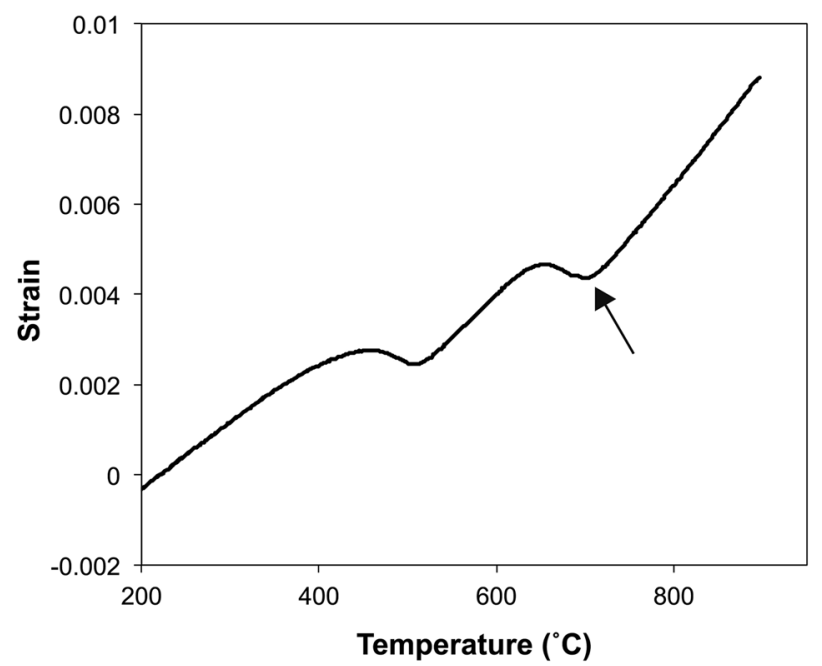

(a)

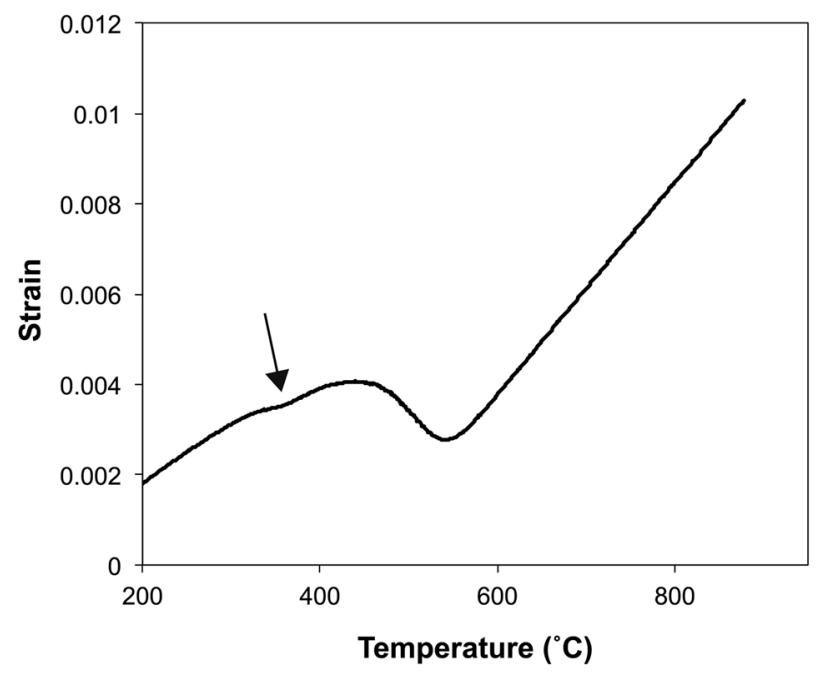

(c)

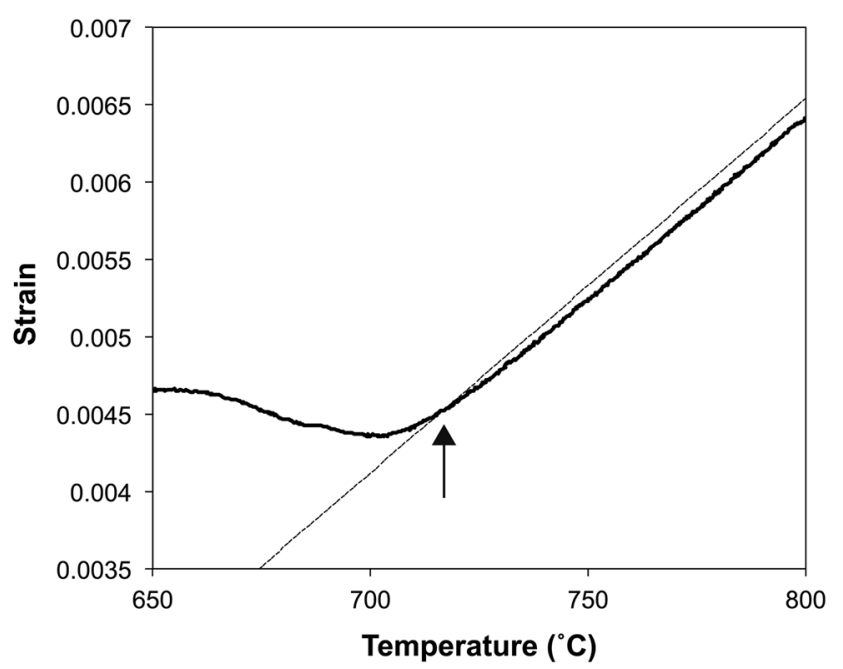

(b)

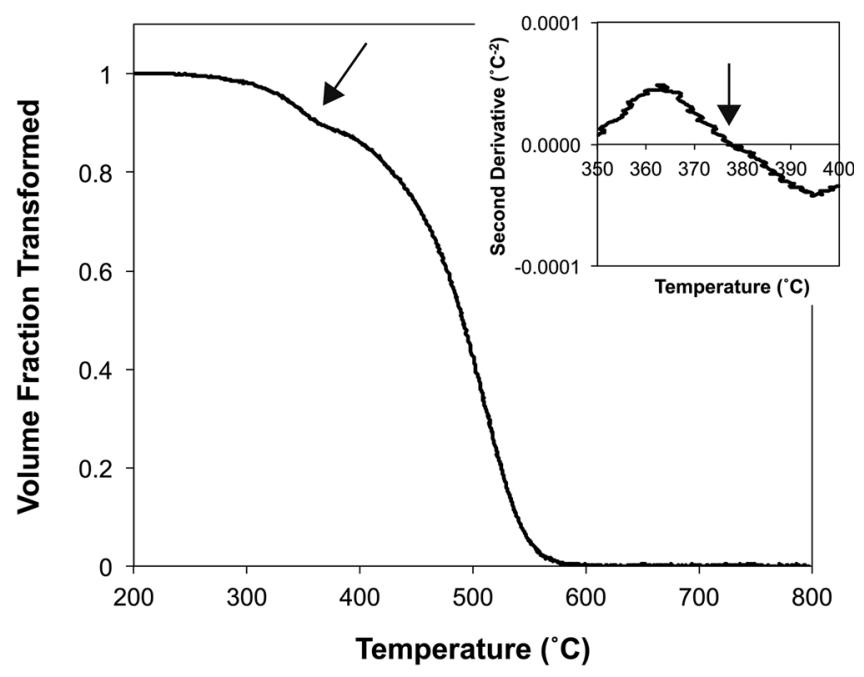

(d)

Fig. 2-Dilatometry: $(a)$ an example of a strain curve displaying two distinctive changes in slope that were assessed using (b) the offset method to find the transformation T. (c) An example of a strain curve with two transformations in quick succession, for which the transformation T was calculated by finding the second derivative, see $(d)$.

was simply that associated with the measurement of retained austenite (see below).

SXRD was used to characterize the fractions of retained austenite in all the samples in the as-cooled condition. The P07 High-Energy Materials Science (HEMS) beamline at the Deutsches Elektronen-Synchrotron facility (DESY, Germany) was used to provide a high-flux $100 \mathrm{kV}$ beam measuring $1 \times 1 \mathrm{~mm}$ in cross section. Debye-Scherrer rings were captured on a Perkin Elmer XRD 1621 Flat Panel 2D area detector, which had a pixel size of $200 \times 200 \mathrm{um}$. The sample-detector distance was set such that at least five diffraction rings from each phase (austenite and ferrite) could be measured. 2D diffraction data were converted to 1D intensity $v s 2 \theta$ using the Fit2D program ${ }^{[27]}$ by fixing the wavelength and refining the sample-detector distance. Phase fractions were calculated using Rietveld analysis in the TOPAS software package. ${ }^{[28]}$
Experimental Debye-Scherrer ring, diffraction spectra together with their fits are shown in Figure 3. Uncertainties associated with phase fractions were considered to arise from two sources: the volume of material sampled (i.e., how representative this was), and from the fitting procedure. Given the large gauge volume (approximately $1 \times 1 \times 4 \mathrm{~mm}$, which would have spanned many prior dendrite arms), it was assumed that all the uncertainty arose from the fitting in TOPAS. Uncertainties associated with instrument and microstructural parameters were found to alter the predicted phase fractions by up to $1 \mathrm{pct}$, so this error was added to all measurements.

For analysis using optical microscopy and SEM, samples were prepared by standard metallographic routes and etched in 2 pet Nital. An FEI Quanta 650 SEM was used to observe the transformed microstructures using an accelerating voltage of $20 \mathrm{kV}$ in 


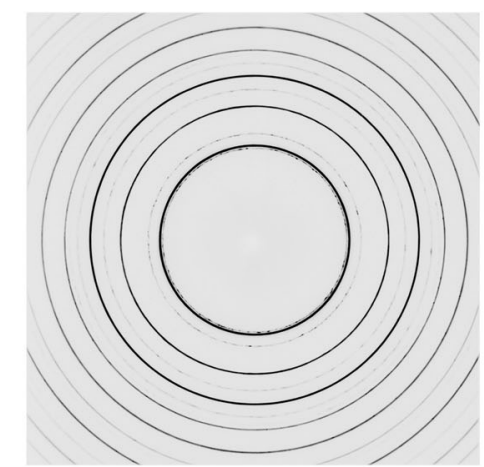

(a)

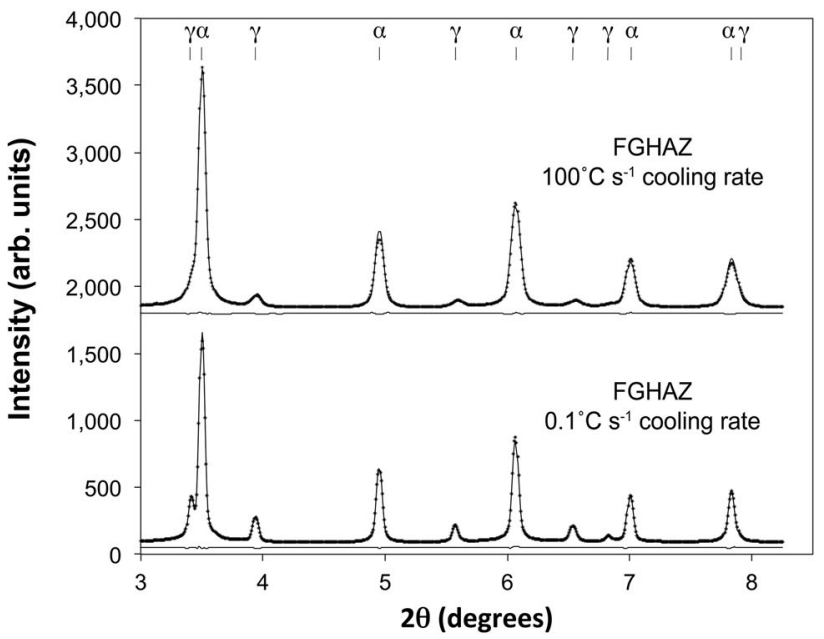

(b)

Fig. 3-(a) Debye-Scherrer ring captured using a 2D area detector for a FGHAZ sample cooled at $0.1{ }^{\circ} \mathrm{C} \mathrm{s}^{-1},(b)$ results of $2 \mathrm{D}$ integration and Rietveld refinement for FGHAZ samples cooled at 0.1 and $100{ }^{\circ} \mathrm{C} \mathrm{s}^{-1}$. The experimental data points are labelled with circular points, the Reitveld fit with a solid line, and the residual displayed below.

secondary-electron imaging mode. The same microscope was also used to assess prior austenite grain sizes through electron back-scatter diffraction (EBSD), with grains reconstructed using the MTEX Matlab toolbox ${ }^{[29]}$ (this technique was only applied to samples cooled at $100{ }^{\circ} \mathrm{C} \mathrm{s}^{-1}$ that contained nearly $100 \mathrm{pct}$ martensite). Austenite grain sizes were also assessed by a thermal etching procedure, which involved exposing a polished surface of the steel to an inert atmosphere during the austenitization step. A linear intercept analysis was used to estimate grain sizes from thermally etched samples. Overall 55 grains were assessed for each of the austenitization steps.

For TEM, thin foils were prepared by grinding material to $100 \mu \mathrm{m}$, punching out discs $3 \mathrm{~mm}$ in diameter, and electropolishing in 20 pct perchloric acid in methanol using a Struers Tenupol-5 at $-30^{\circ} \mathrm{C}$ and a voltage of $17 \mathrm{~V}$. Bright- and dark-field images and selected-area electron diffraction patterns (SADPs) were taken using an FEI Talos TEM at $200 \mathrm{kV}$. The carbon distribution in the microstructure was revealed using nanoscale secondary ion mass spectroscopy (NanoSIMS). A Cameca NanoSIMS 50L was used with a 16 $\mathrm{keV} \mathrm{Cs}^{+}$primary ion beam with a current of 0.8 to 2.7 $\mathrm{pA}$ and aligned to detect ${ }^{12} \mathrm{C}^{-},{ }^{12} \mathrm{C}_{2}^{-}$and ${ }^{12} \mathrm{C}^{14} \mathrm{~N}^{-} . \mathrm{Cs}^{+}$ ions were implanted into the surface prior to imaging to achieve a dose of $1 \times 10^{17}$ ions $\mathrm{cm}^{-2}$ to ensure that each imaged area was at steady state and to remove any native oxide. Image analysis was completed using the L'Image software package. ${ }^{[30]}$

\section{MODELING}

Phase transformation kinetics were predicted using the well-known model due to $\mathrm{Li}$ et al. model, ${ }^{[3]}$ implemented within a finite element framework originally developed by Hamelin et al. ${ }^{[10]}$ to predict residual stresses in the Net Task Group 5 international weld residual stress simulation and measurement benchmark. NeT TG5 is an autogenous TIG-welded beam manufactured from SA508 $\mathrm{Gr} 3 \mathrm{Cl} 1$ steel, so the approach developed in Reference 10 and since applied successfully to high energy electron beam welds in the same material ${ }^{[32]}$ should transfer directly to the dilatometry experiments reported here.

The full solid state phase transformation model handles austenite formation during heating, austenite grain growth in the CGHAZ, and austenite decomposition during cooling. ${ }^{[31]}$ Here, we are concerned only with modeling austenite decomposition, as the average austenite grain size in the test specimens is known, and does not need to be calculated. Diffusive and mixed diffusive-displacive austenite decomposition into ferrite and cementite based micro-constituents are handled separately from martensite formation.

The reaction kinetics for diffusive and mixed diffusive-displacive austenite decomposition are described using the semi-empirical model originally developed by Kirkaldy and Venugopalan, ${ }^{[33]}$ and later modified by Li et al. ${ }^{[31]}$ Here, the time $\tau$ required for a volume fraction $X$ of a given phase to transform at a constant temperature $T[\mathrm{~K}]$ is:

$$
\tau(\mathrm{X}, \mathrm{T})=\frac{F(\mathrm{C}, \mathrm{Mn}, \mathrm{Si}, \mathrm{Ni}, \mathrm{Cr}, \mathrm{Mo}, \mathrm{G})}{\Delta T^{n} \exp \left(-\frac{Q}{\mathrm{R} T}\right)} S(X)
$$

where

$F$ : a function dependent upon the ferritic phase of interest (as detailed in Table III: FC for ferrite formation, $\mathrm{PC}$ for pearlite formation and $\mathrm{BC}$ for bainite formation), the chemical composition of the steel and the prior-austenite grain size (expressed as an ASTM grain size number, $G$ ),

$\Delta T$ : the amount of undercooling beneath the equilibrium transformation temperature,

$n$ : the exponent of undercooling; an empirically derived constant, whose value varies with the effective diffusion mechanism (volume or boundary diffusion) (see Table III),

$Q$ : the activation energy for the diffusional SSPT reaction, with $Q=27500 \mathrm{cal} \mathrm{mol}^{-1} \mathrm{~K}^{-1}$ 
Table III. Components of the Diffusive Transformation Equations

\begin{tabular}{lccc}
\hline & $\mathrm{F}($ composition, $\mathrm{G})$ & Undercooling $(\Delta T)$ & Exponent of Undercooling $(n)$ \\
\hline Ferrite Reaction & $\frac{F C}{2^{0.41 G}}$ & $A e_{3}-T$ & 3 \\
Pearlite Reaction & $\frac{P C}{2^{0.32 G}}$ & $A e_{1}-T$ & 3 \\
Bainite Reaction & $\frac{B C}{2^{0.29 G}}$ & $B_{s}-T$ & 2 \\
\hline
\end{tabular}

$S(X)$ : a sigmoidal function representing the rates observed during isothermal transformation:

$$
S(X)=\int_{0}^{X} \frac{d X}{X^{0.4(1-X)}(1-X)^{0.4 X}}
$$

The reaction equations for ferrite $\left(\tau_{\mathrm{F}}\right)$, pearlite $\left(\tau_{\mathrm{P}}\right)$, and bainite $\left(\tau_{\mathrm{B}}\right)$ are derived by substituting the data in Table III into Eq. [3].

The coefficients FC, PC, and BC are dependent on the chemical composition of the steel, in wt pct, and are expressed by the following equations ${ }^{[31]}$ :

$$
\begin{aligned}
\mathrm{FC}= & \exp (1.00+6.31 \mathrm{C}+1.78 \mathrm{Mn}+0.31 \mathrm{Si}+1.12 \mathrm{Ni} \\
& +2.70 \mathrm{Cr}+4.06 \mathrm{Mo})
\end{aligned}
$$

$$
\begin{aligned}
\mathrm{PC}= & \exp (-4.25+4.12 \mathrm{C}+4.36 \mathrm{Mn}+0.44 \mathrm{Si} \\
& +1.71 \mathrm{Ni}+3.33 \mathrm{Cr}+5.19 \sqrt{\mathrm{Mo}})
\end{aligned}
$$

$$
\begin{aligned}
\mathrm{BC}= & \exp (-10.23+10.18 \mathrm{C}+0.85 \mathrm{Mn} \\
& +0.55 \mathrm{Ni}+0.90 \mathrm{Cr}+0.36 \mathrm{Mo})
\end{aligned}
$$

The bainite start temperature $\mathrm{B}_{\mathrm{s}}$ is also a function of chemical composition $^{[31]}$ :

$B_{s}=637-58 \mathrm{C}-35 \mathrm{Mn}-15 \mathrm{Ni}-34 \mathrm{Cr}-41 \mathrm{Mo}$

Direct thermodynamic calculation using THERMO$\mathrm{CALC}^{[34]}$ was used to estimate $A e_{1}$ and $A e_{3}$, the lower and upper equilibrium temperatures for the start and finish of austenization. This gave values of $A e_{1}=$ $645{ }^{\circ} \mathrm{C}$ and $A e_{3}=799{ }^{\circ} \mathrm{C}$. These differ somewhat from the values proposed by the Grange, ${ }^{[35,36]}$ or Eldis formulae ${ }^{[37]}$ the average of which is used in Reference 10 .

The $A c_{1}$ and $A c_{3}$ temperatures are calculated based on Eqs. [9] and [10], which are linear function of the heating rate, $\dot{T}\left({ }^{\circ} \mathrm{Cs}^{-1}\right)^{[38]}$ At every increment of the simulation the $A c_{1}$ and $A c_{3}$ are calculated.

$$
\begin{aligned}
& A_{C 3}=0.4 \dot{T}+840 \\
& A_{C 1}=0.4 \dot{T}+758
\end{aligned}
$$

Equations [3] through [8] describe isothermal transformations as expressed in a TTT diagram. These were implemented using the additive rules of Scheil ${ }^{[39]}$ and Avrami ${ }^{[40-42]}$ to obtain the CCT behavior. Thus, the time to nucleate a ferritic phase is calculated by solving

$$
\int_{0}^{t_{n}} \frac{d t}{\tau(0.01, T)}=1 .
$$

Once a ferritic phase has nucleated, the volume fraction $X$ is calculated from Reference 10 .

$$
X=\int_{t_{n}}^{t} \frac{d t}{\tau(1.0, T)-\tau(0.01, T)}
$$

until growth is complete. The numerical implementation of Eq. [12] assumes that growth is complete at $X=1$. It should be noted that $X$ equal to one corresponds to the maximum attainable fraction of each phase. For ferrite, the equilibrium volume fraction is taken to be 0.9 , which was approximated to be the maximum fraction of allotriomorphic ferrite attainable during cooling, as estimated according to the contents of the carbon and alloying elements in SA508 steel. Accordingly, the maximum volume fraction of pearlite is 0.1 . For bainite and martensite, the maximum volume fraction is allowed to be one. Because ferrite/pearlite formation is unlikely in this steel at the cooling rates experienced during welding, this simplification was judged acceptable.

Martensite formation is handled in a simpler fashion. The martensite start temperature, $M_{\mathrm{s}}$, is defined using the formula originally proposed by Andrews ${ }^{[36]}$ and later modified by Kung and Rayment ${ }^{[43]}$ This is solely dependent on chemical composition:

$$
\begin{aligned}
M_{\mathrm{S}}= & 539-423 \mathrm{C}-30.4 \mathrm{Mn}-17.7 \mathrm{Ni}-12.1 \mathrm{Cr} \\
& -7.5 \mathrm{Mo}+10.0 \mathrm{Co}-7.5 \mathrm{Si}
\end{aligned}
$$

For the martensite transformation, the Koistinen-Marburger model ${ }^{[44]}$ is employed, according to which the martensite fraction is expressed as

$$
X=X_{R A}\left\{1-\exp \left[-A\left(M_{s}-T\right)\right]\right\},
$$

where $X_{\mathrm{RA}}$ is the fraction of remaining austenite for martensite transformation; $M_{\mathrm{s}}$ is martensite start 
temperature and $A$ is a material parameter $(\mathrm{A}=0.035$ $\mathrm{K}^{-1}$ for SA508 steel. $^{[38]}$

The phase transformation model was implemented in Abaqus ${ }^{[45]}$ using a series of Abaqus FORTRAN user subroutines. These subroutines were originally developed by Hamelin et al. ${ }^{[10]}$ and are currently being co-developed at the University of Manchester. A single-element model was used, with the dilatometer heating and cooling cycle for each case defined as a temperature boundary condition. The material properties used for SA508 Gr.3 Cl.1 steel were based on those presented in References 46 and 47 with some changes made to the thermal expansion coefficients to match the observed heating and cooling behavior of the dilatometry tests in the absence of phase transformation. The austenite grain size $(G)$ was set to the measured average values of 11 microns for experiments cooled from $900{ }^{\circ} \mathrm{C}$, and 65 microns for experiments cooled from $1200{ }^{\circ} \mathrm{C}$.

Analyses were run for all 22 heat treatments investigated, producing the following outputs: (i) Predictions of the dilation curves - the quantity actually measured in the tests. (ii) Predictions of the start temperatures for each of the micro-constituents formed on austenite decomposition. (iii) Predictions of the final volume fractions of each micro-constituent.

\section{RESULTS}

\section{A. Experimental}

The results of the dilatometry investigations/SXRD are shown in Tables IV and V, with the resulting CCT diagram plotted in Figure 4. The calculated $\mathrm{Ae}_{3}$ temperature of $799{ }^{\circ} \mathrm{C}$ is used as the time $=0$ point in Figure 4. In Table IV and Figure 4, the Widmanstätten ferrite and bainite transformations are grouped together. The reasons for this grouping are discussed in detail in Section $\mathrm{V}-\mathrm{A}$, but essentially this was done because they appeared to form in similar temperature range and their dilatational signals could not be separated.

Increasing the cooling rate clearly has a marked effect on the transformation behavior. As the cooling rate is increased, the dominant microconstituent changes from allotriomorphic ferrite at slow cooling rates (transformation $\mathrm{T}$ around $700{ }^{\circ} \mathrm{C}$ ), to Widmanstätten ferrite/ bainite at intermediate cooling rates (transformation $\mathrm{T}$ in the range $500-600^{\circ} \mathrm{C}$ ) to martensite at fast cooling rates (transformation $\mathrm{T}$ around $400^{\circ} \mathrm{C}$ ). The increase in hold temperature from $900^{\circ} \mathrm{C}$ to $1200^{\circ} \mathrm{C}$ generally increases the fractions of Widmanstätten ferrite/bainite and/or martensite present. It is apparent that the formation of allotriomorphic ferrite depressed the

Table IV. Phase and Microconstituents Volume Fraction and Transformation Start Temperature for $900{ }^{\circ} \mathrm{C}$ Peak Temperature

\begin{tabular}{|c|c|c|c|c|c|c|c|c|}
\hline $\begin{array}{l}\text { Cooling } \\
\left({ }^{\circ} \mathrm{C} \mathrm{s}^{-1}\right)\end{array}$ & Rate & $\begin{array}{c}\text { Ferrite } \\
\text { Start }\left({ }^{\circ} \mathrm{C}\right)\end{array}$ & $\begin{array}{l}\text { Ferrite } \\
\text { (Pct) }\end{array}$ & $\begin{array}{l}\text { Widmanstätten/Bai- } \\
\text { nite Start }\left({ }^{\circ} \mathrm{C}\right)\end{array}$ & $\begin{array}{l}\text { Widmanstätten/ } \\
\text { Bainite (Pct) }\end{array}$ & $\begin{array}{c}\text { Martensite } \\
\text { start }\left({ }^{\circ} \mathrm{C}\right)\end{array}$ & $\begin{array}{l}\text { Martensite } \\
\quad(\mathrm{Pct})\end{array}$ & $\begin{array}{c}\text { Retained } \\
\text { Austenite (Pct) }\end{array}$ \\
\hline 0.1 & & 732 & $55 \pm 2$ & 525 & $36 \pm 2$ & & & $9 \pm 1$ \\
\hline 0.2 & & 725 & $38 \pm 2$ & 546 & $51 \pm 2$ & & & $11 \pm 1$ \\
\hline 0.5 & & 712 & $22 \pm 3$ & 569 & $65 \pm 3$ & & & $13 \pm 1$ \\
\hline 1 & & 706 & $12 \pm 3$ & 585 & $75 \pm 3$ & & & $13 \pm 1$ \\
\hline 2 & & 665 & $4 \pm 4$ & 600 & $83 \pm 5$ & & & $13 \pm 1$ \\
\hline 5 & & & & 572 & $79 \pm 4$ & 379 & $11 \pm 4$ & $10 \pm 1$ \\
\hline 10 & & & & 564 & $72 \pm 6$ & 396 & $20 \pm 6$ & $8 \pm 1$ \\
\hline 20 & & & & 570 & $43 \pm 6$ & 405 & $51 \pm 6$ & $6 \pm 1$ \\
\hline 50 & & & & 562 & $12 \pm 3$ & 405 & $83 \pm 3$ & $5 \pm 1$ \\
\hline 100 & & & & 499 & $2 \pm 2$ & 430 & $93 \pm 2$ & $5 \pm 1$ \\
\hline
\end{tabular}

Table V. Phase and Microconstituents Volume Fraction and Transformation Start Temperature for $1200{ }^{\circ} \mathrm{C}$ Peak Temperature

\begin{tabular}{|c|c|c|c|c|c|c|c|c|}
\hline $\begin{array}{l}\text { Cooling } \\
\left({ }^{\circ} \mathrm{C} \mathrm{s}^{-1}\right)\end{array}$ & Rate & $\begin{array}{c}\text { Ferrite } \\
\text { Start }\left({ }^{\circ} \mathrm{C}\right)\end{array}$ & $\begin{array}{l}\text { Ferrite } \\
\text { (Pct) }\end{array}$ & $\begin{array}{l}\text { Widmanstätten/Bai- } \\
\text { nite Start }\left({ }^{\circ} \mathrm{C}\right)\end{array}$ & $\begin{array}{l}\text { Widmanstätten/ } \\
\text { Bainite (Pct) }\end{array}$ & $\begin{array}{l}\text { Martensite } \\
\text { Start }\left({ }^{\circ} \mathrm{C}\right)\end{array}$ & $\begin{array}{l}\text { Martensite } \\
\quad(\mathrm{Pct})\end{array}$ & $\begin{array}{c}\text { Retained } \\
\text { Austenite (Pct) }\end{array}$ \\
\hline 0.1 & & 700 & $11 \pm 4$ & 591 & $82 \pm 4$ & & & $7 \pm 1$ \\
\hline 0.2 & & & & 564 & $90 \pm 1$ & & & $10 \pm 1$ \\
\hline 0.5 & & & & 562 & $90 \pm 1$ & & & $10 \pm 1$ \\
\hline 1 & & & & 553 & $91 \pm 1$ & & & $9 \pm 1$ \\
\hline 2 & & & & 543 & $96 \pm 1$ & & & $4 \pm 1$ \\
\hline 5 & & & & 517 & $61 \pm 14$ & 393 & $35 \pm 14$ & $4 \pm 1$ \\
\hline 10 & & & & 482 & - & - & — & $4 \pm 1$ \\
\hline 20 & & & & & & 431 & $97 \pm 1$ & $3 \pm 1$ \\
\hline 50 & & & & & & 435 & $97 \pm 1$ & $3 \pm 1$ \\
\hline 100 & & & & & & 393 & $97 \pm 1$ & $3 \pm 1$ \\
\hline
\end{tabular}


transformation temperature of any subsequent Widmanstätten ferrite/bainite, with the effect increasing in strength with greater allotriomorphic ferrite percentage. Similarly, there is an indication that formation of Widmanstätten ferrite/bainite before martensite also depressed the martensite start temperature (see FGHAZ data, in particular).

For the CGHAZ sample cooled at $10^{\circ} \mathrm{C} \mathrm{s}^{-1}$, no martensite start temperature is added to the diagram. This is because there was no clear second transformation event in the dilatometry curve following the formation of Widmanstätten ferrite/bainite around $480{ }^{\circ} \mathrm{C}$. Similarly, for the CGHAZ samples cooled at $20^{\circ} \mathrm{C} \mathrm{s}^{-1}$ and $50{ }^{\circ} \mathrm{C} \mathrm{s}^{-1}$, which transformed around $430{ }^{\circ} \mathrm{C}$, there is the possibility that a small percentage of Widmanstätten ferrite/bainite formed in the samples. However, there was no distinguishable signal, and the temperatures of transformation are used as martensite start temperatures owing to their proximity to the $M_{S}$ temperatures measured in other samples.

Figure 5 shows the change in retained austenite percentage as a function of heat treatment as measured using SXRD. For the samples held at $900{ }^{\circ} \mathrm{C}$, retained austenite levels increased from 9 pct at $0.1{ }^{\circ} \mathrm{C} \mathrm{s}^{-1}$ to 13 pct between 0.5 and $2{ }^{\circ} \mathrm{C} \mathrm{s}^{-1}$ cooling rate, before steadily decreasing with increasing cooling rate to plateau around 5 pct. For samples held at $1200{ }^{\circ} \mathrm{C}$, the peak austenite levels were found for 0.2 and $0.5^{\circ} \mathrm{C}$ $\mathrm{s}^{-1}$ cooling rates, and decreased to plateau around 3 pct.

The results of thermal etching, Figure 6, and EBSD analysis estimated the prior-austenite grain size to be 11 $\pm 2 \mu \mathrm{m}$ for the samples held at $900{ }^{\circ} \mathrm{C}$ (FGHAZ) and 65 $\pm 16 \mu \mathrm{m}$ for samples held at $1200{ }^{\circ} \mathrm{C}$ (CGHAZ).

The results of optical microscopy were consistent with those from dilatometry. Slow-cooled FGHAZ samples were found to comprise large quantities of allotriomorphic ferrite interspersed with carbide-rich pockets

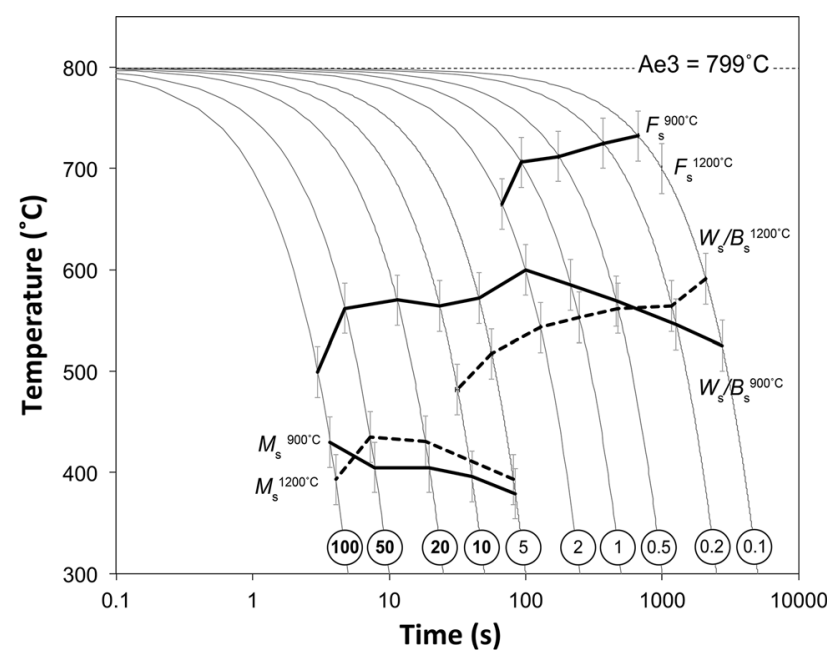

Fig. 4 - Continuous cooling transformation diagrams measured using dilatometry for the two austenitization temperatures investigated. Cooling curves for each quenching rate are superimposed, with the rate indicated at the bottom of each curve. The rates applicable to the HAZs of typical welding processes are in bold $\left(\geq 10^{\circ} \mathrm{C} \mathrm{s}^{-1}\right)$. The 1 pct transformation temperatures for allotriomorphic ferrite, Widmanstätten ferrite/bainite, and martensite are plotted.

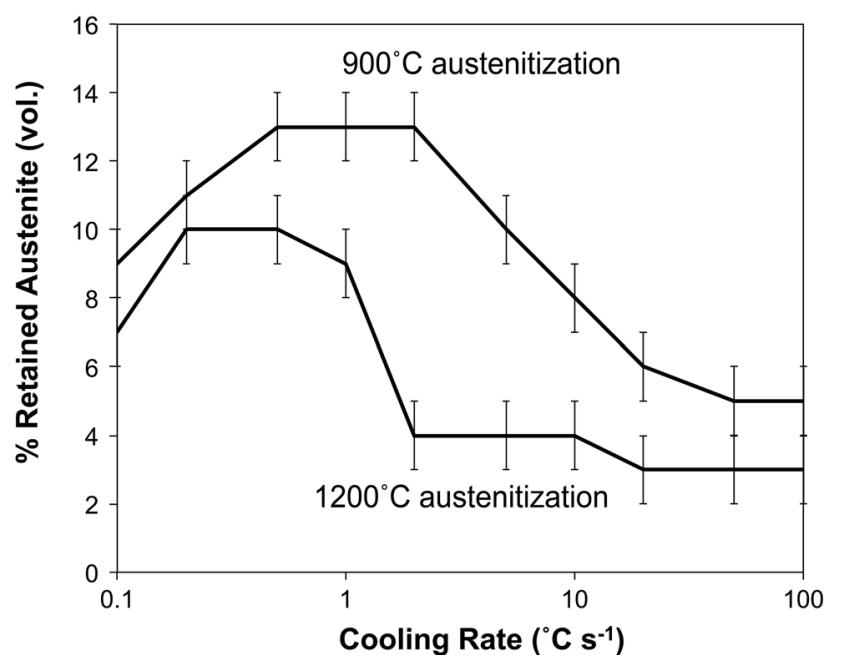

Fig. 5-The variation in percentage of retained austenite with cooling rate as found using SXRD.

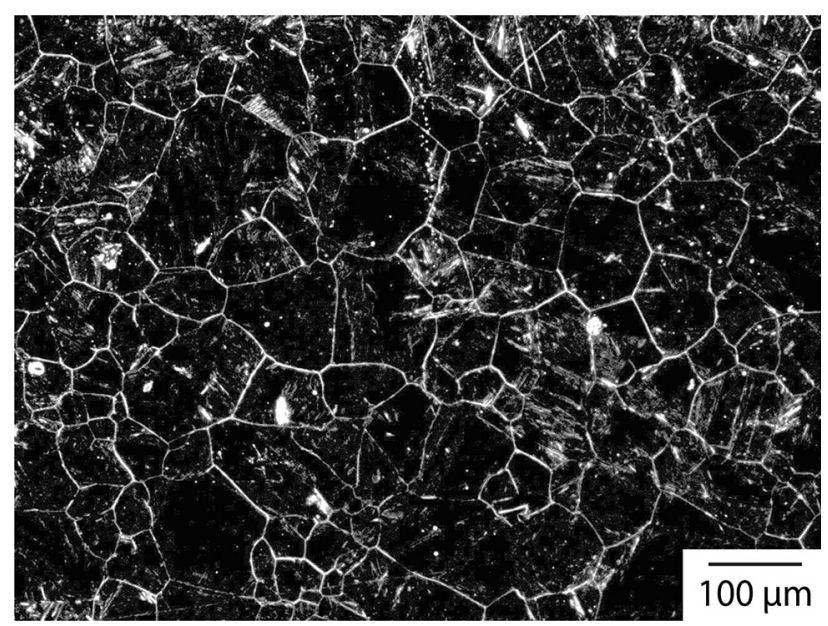

Fig. 6-Example of a dark-field optical micrograph of a thermally etched CGHAZ sample.

(labeled CP), Figure 7(a), whilst the CGHAZ comprised more Widmanstätten ferrite $\left(\alpha_{w}\right)$, Figure $7(b)$, with the carbide-rich pockets occupying the spaces between ferritic laths. Fast-cooled microstructures consisted of 100 pct martensite, Figure 7(e) through (f), but the complexity of the microstructures produced at intermediate cooling rates meant that microconstituents could not easily be assessed using optical microscopy, e.g., Figure 7(c).

SEM revealed features consistent with martensite-austenite (MA) islands alongside ferrite and carbide-rich pockets in slow-cooled material, Figures 8(a) and (b). At intermediate cooling rates, complex mixed microstructures were formed. Figure 8(c) shows FGHAZ material cooled at $5{ }^{\circ} \mathrm{C} \mathrm{s}^{-1}$, which comprised Widmanstätten ferrite alongside MA islands, and regions consisting of bainite $\left(\alpha_{\mathrm{b}}\right)$ and/or autotempered martensite (AT $\alpha^{\prime}$ ) - these could not be distinguished. 

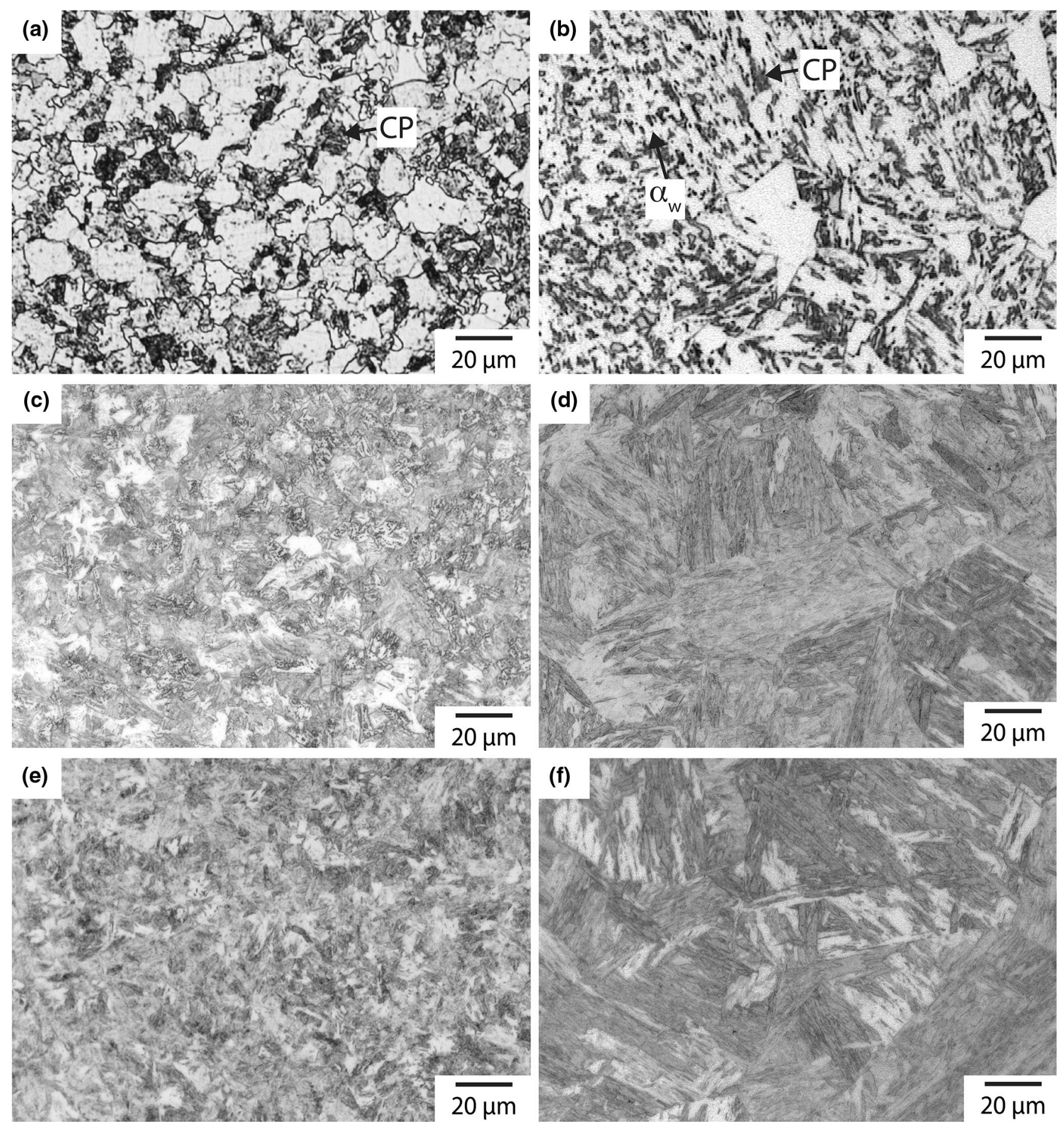

Fig. 7- Optical micrographs of the microstructures obtained at different cooling rates in the FGHAZ [micrographs $(a),(c)$ and $(e)$ ] and CGHAZ [micrographs $(b),(d)$ and $(f)$ ] conditions. Cooling rates were $0.1{ }^{\circ} \mathrm{C} \mathrm{s}^{-1}$ for (a) and (b), $20{ }^{\circ} \mathrm{C} \mathrm{s}^{-1}$ for (c) and (d), and $100{ }^{\circ} \mathrm{C} \mathrm{s}{ }^{-1}$ for (e) and (f).

CGHAZ material cooled at $5{ }^{\circ} \mathrm{Cs}^{-1}$ also comprised Widmanstätten ferrite and MA islands, Figure 8(d), and regions with fine lath structures consistent with bainitic ferrite (although, again, autotempered martensite could not be ruled out). Large regions of what appeared to be autotempered martensite were observed in rapidly cooled CGHAZ samples, Figure 8(f), but were not observed in FGHAZ material, Figure 8(e).
The presence of martensite-austenite islands in slow-cooled samples was confirmed using TEM imaging and electron diffraction, Figure 9. Twinned martensite was observed alongside retained austenite, as demonstrated using dark field imaging. NanoSIMs was used to confirm that the suspected MA regions were enriched in carbon, Figure 10. The top of this figure shows results from a FGHAZ cooled at $0.1{ }^{\circ} \mathrm{C} \mathrm{s}^{-1}$. Two carbon 

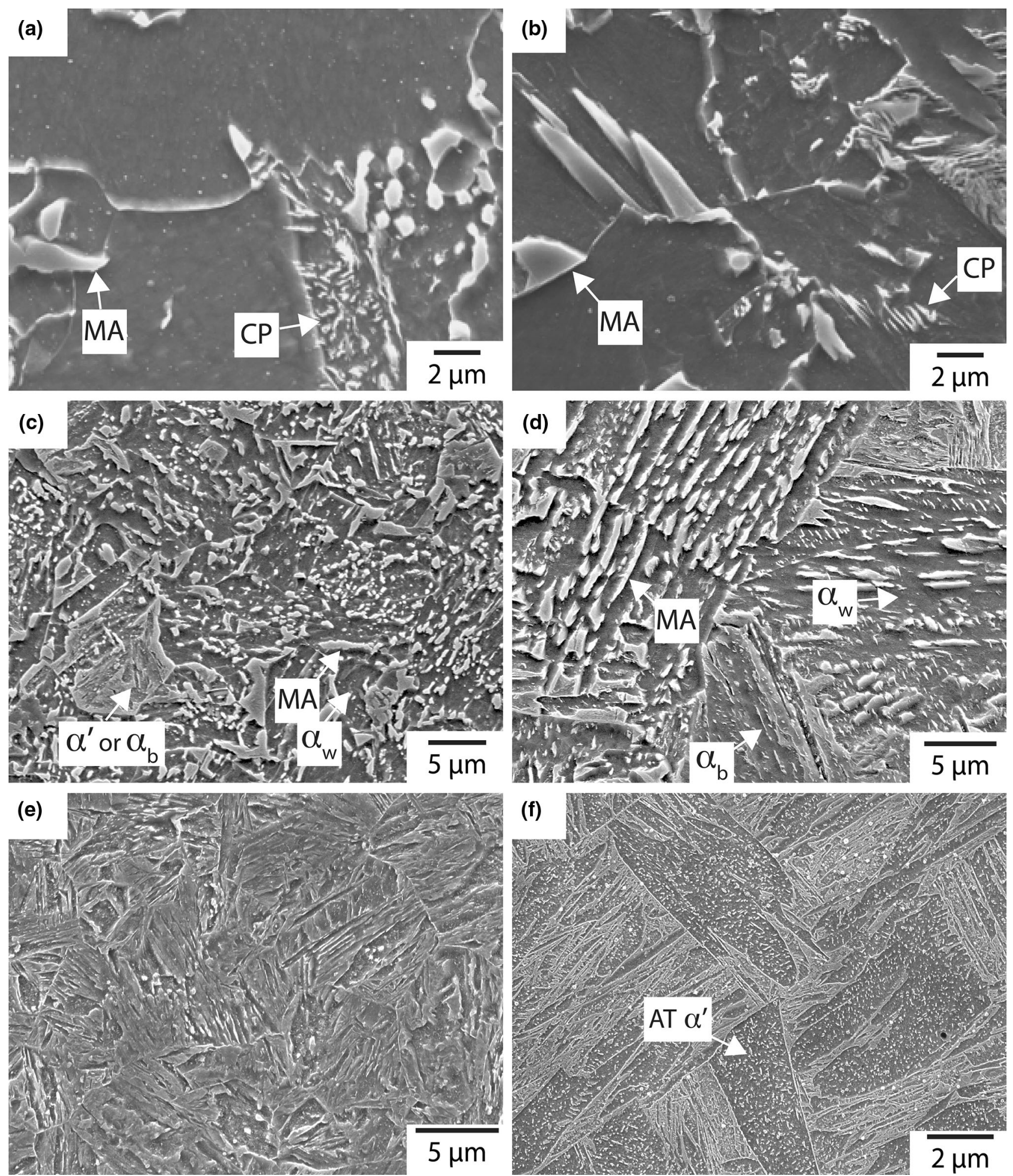

Fig. 8- SEM secondary-electron images of the microstructures obtained at different cooling rates in the FGHAZ (micrographs $(a)$, $(c)$ and $(e)$ ) and CGHAZ (micrographs $(b),(d)$ and $(f)$ ) conditions. Cooling rates were $0.1^{\circ} \mathrm{C} \mathrm{s}^{-1}$ for (a) and (b), $5^{\circ} \mathrm{C} \mathrm{s}^{-1}$ for (c) and (d), and $100^{\circ} \mathrm{C} \mathrm{s}^{-1}$ for (e) and (f).

signals were captured, ${ }^{12} \mathrm{C}^{-}$, corresponding to a single carbon atom, and ${ }^{12} \mathrm{C}_{2}^{-}$, corresponding to two carbon atoms joined together. The ${ }^{12} \mathrm{C}^{-}$counts per pixel were the same in both regions 1 and 2 labelled at the top of Figure 10, indicating a similar level of carbon enrichment, but the ${ }^{12} \mathrm{C}_{2}^{-}$was a factor of two higher in region 

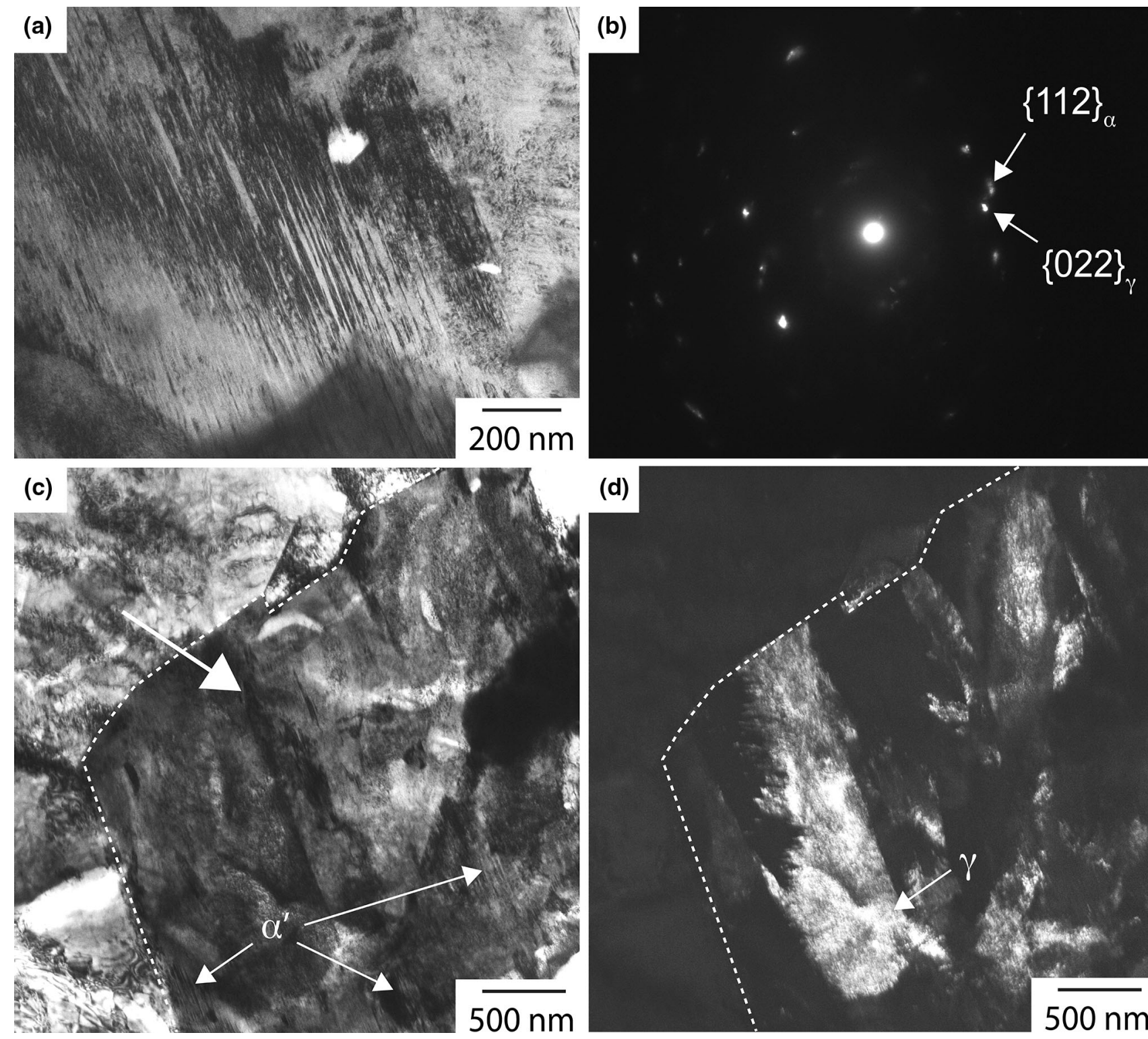

(d)

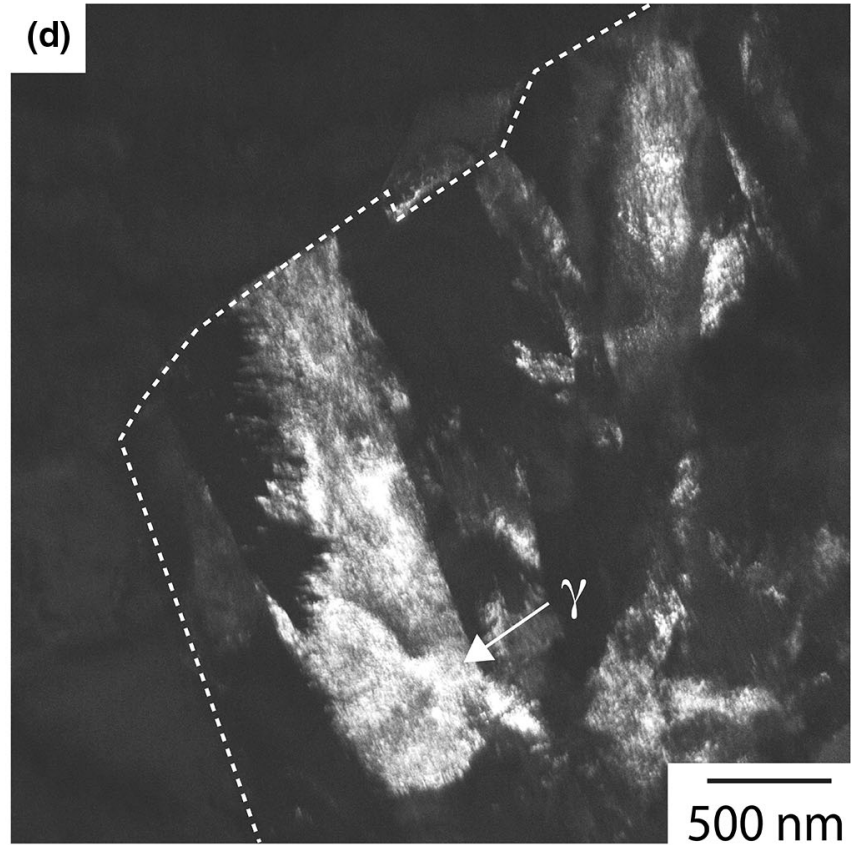

Fig. 9-For FGHAZ sample cooled at $0.1{ }^{\circ} \mathrm{C} \mathrm{s}^{-1}$ : (a) TEM bright-field image of twinned martensite, $(b)$ SADP showing ferrite and austenite reflections, which was taken from region in $(c)$. Martensite twins are evident inside the MA region highlighted, and dark-field imaging using the $\{022\} \gamma$ reflection, $(d)$, was used to reveal the austenite present.

1 , consistent with the formation of carbides in this region (the ${ }^{12} \mathrm{C}_{2}^{-}$signal is strong from carbides since carbon atoms are surrounded by each other). The base of Figure 10 shows the same signals for a FGHAZ sample cooled at $1{ }^{\circ} \mathrm{C} \mathrm{s}^{-1}$. Regions with high ${ }^{12} \mathrm{C}^{-}$ signal are widespread, consistent with the large fraction of retained austenite measured using SXRD (13 pct). Strong ${ }^{12} \mathrm{C}_{2}^{-}$signals from carbide-rich regions are scattered through the structure. The spots with strong ${ }^{12} \mathrm{C}^{14} \mathrm{~N}^{-}$signals found in both samples, indicative of enrichment in nitrogen, are likely to have been associated with AlN particles, although this was not confirmed with any other observations. AlN particles are known to restrict austenite grain growth in SA508 Grade 3. ${ }^{[48]}$

\section{B. Comparison with Modeling}

A comparison of predicted and experimentally determined CCT diagrams and microconstituent percentages are shown in Figures 11 and 12, respectively. There is, in general, reasonable agreement between experimental and predicted start temperatures, and the model adequately captures the effect of changing the prior austenite grain size. The only significant disagreements between measurement and prediction are as follows: (i) start temperatures for the allotriomorphic ferrite transformation in the CGHAZ, and start temperatures for the Widmanstätten ferrite/bainite transformation in the FGHAZ, where the model predicts a lower start temperature in both cases (note the model only predicts 

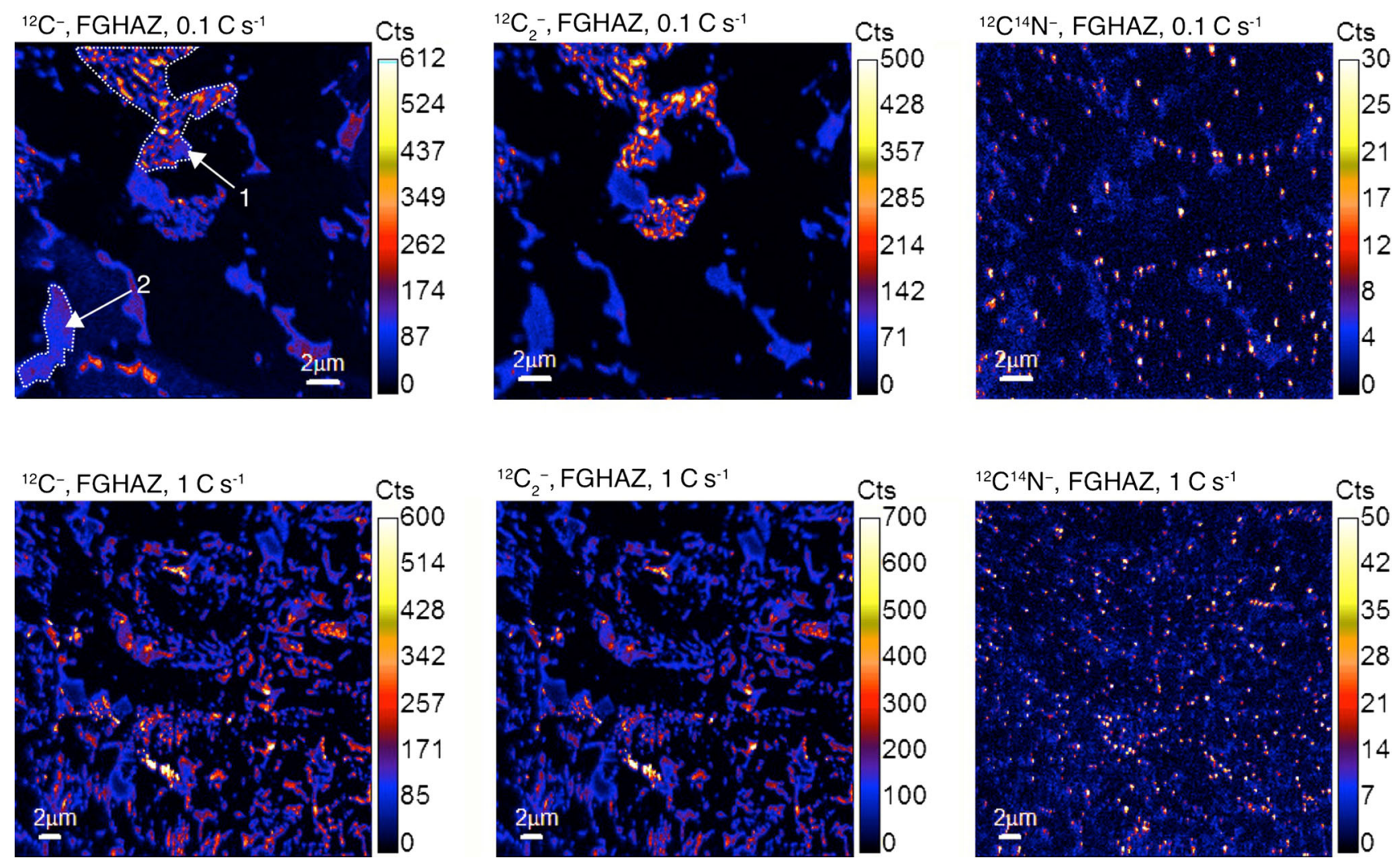

Fig. 10-NanoSIMS results for FGHAZ samples cooled at $0.1{ }^{\circ} \mathrm{C} \mathrm{s}^{-1}$ (top) and $1{ }^{\circ} \mathrm{C} \mathrm{s}^{-1}$ (bottom).

bainite, as will be discussed below). (ii) The model over-predicts allotriomorphic ferrite at the slowest cooling rate in the FGHAZ. (iii) The model over-predicts allotriomorphic ferrite in the CGHAZ. (iv) The model predicts bainite formation at cooling rates above $10{ }^{\circ} \mathrm{C} \mathrm{s}^{-1}$ in the CGHAZ. (v) The model does not predict retained austenite in any case.

\section{DISCUSSION}

\section{A. Continuous Cooling Transformation Behavior}

The interpretation of the microstructures of continuously cooled high-strength low-alloy (HSLA) steels is notoriously difficult, particularly if one is aiming to quantify the fractions of each microconstituent present. The optical and SEM micrographs shown in Figures 7 and 8 demonstrate that such quantification is particularly challenging at intermediate cooling rates, where mixed microstructures are prevalent. Metallography must be combined with dilatometry in order to adequately identify transformation start temperatures and calculate estimates for the volume fractions of microconstituents.

The results of all the analysis techniques used in this study complemented each other and revealed a phase transformation behavior that is largely consistent with known theories. Increasing the cooling rate from austenitization decreased the fraction of allotriomorphic ferrite formed by a diffusive reaction and increased the fraction of Widmanstätten ferrite, bainite and martensite, formed by diffusive-displacive and displacive reactions, respectively. Increasing the grain size had a similar effect to increasing cooling rate, which can be understood by recognizing that there are fewer nucleation sites for allotriomorphic ferrite, Widmanstätten ferrite and bainite for large grain sizes.

There is strong evidence that a significant quantity of the ferrite formed at intermediate cooling rates in this study was Widmanstätten ferrite, rather than bainitic ferrite. Carbon is partitioned into austenite during the growth of Widmanstätten ferrite, whereas it is not during the growth of bainite in steels with low $\mathrm{Si}$ contents ( $\mathrm{Si}$ concentrations in excess of $1 \mathrm{wt}$ pct are typically required to stabilize austenite films between bainitic laths by eliminating cementite precipitation $\left.^{[49,50]}\right)$. Hence, bainitic microstructures should not result in high levels of retained austenite (MA islands), and also should not lead to the formation of carbide-rich pockets of material as observed in this study, e.g., Figures 7(b) and 8(b) ${ }^{[23]}$

If we use the retained austenite fractions measured to indicate a greater level of bainitic ferrite over Widmanstätten ferrite, we can surmise that bainitic ferrite began to form in significant fractions at cooling rates of $2{ }^{\circ} \mathrm{C} \mathrm{s}^{-1}$ and above for CGHAZ material. The SEM micrograph shown in Figure 8(d), for a CGHAZ sample cooled at $5{ }^{\circ} \mathrm{C} \mathrm{s}^{-1}$ in which no martensite was measured using dilatometry, appears to confirm this observation. Two morphologies of ferrite are observed - the first consisting of coarse plates free from carbide 


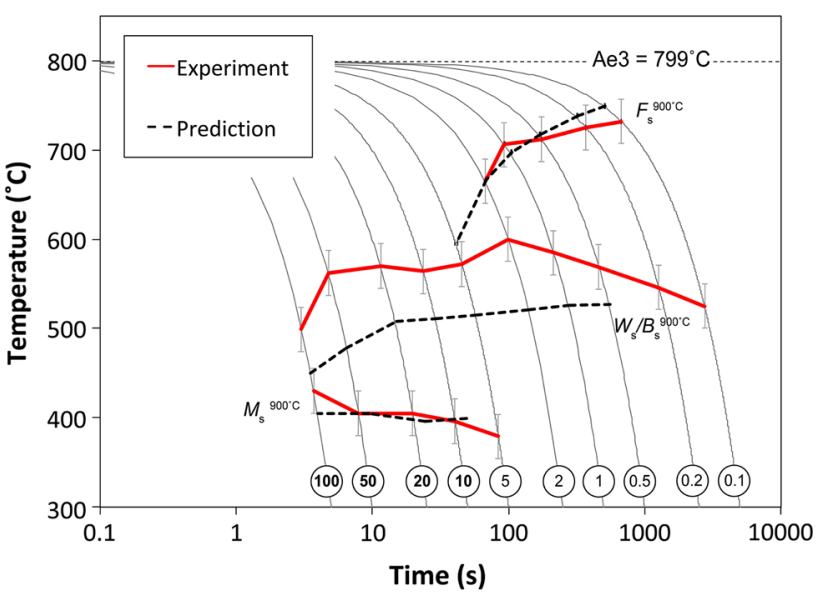

(a)

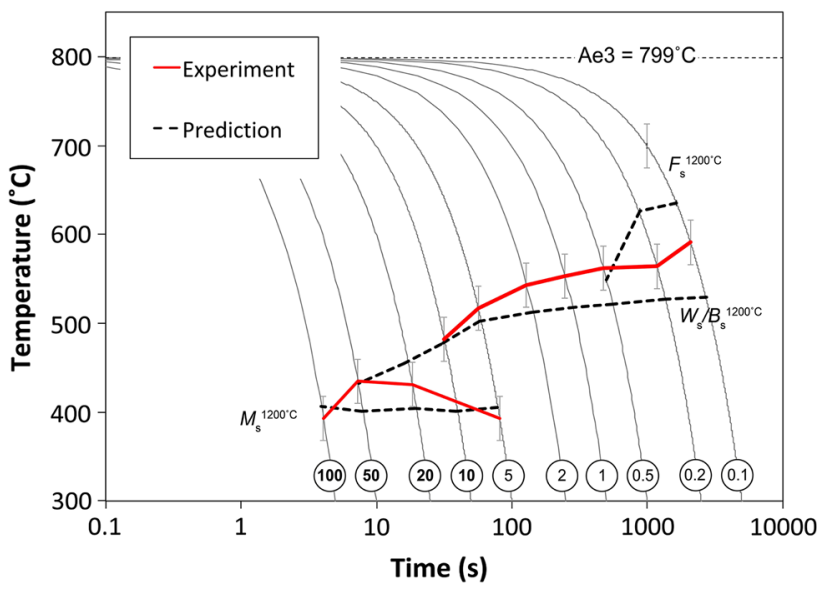

(b)

Fig. 11-Comparison of CCT diagrams obtained from modeling and experiment for (a) FGHAZ and (b) CGHAZ. The rates applicable to the HAZs of typical welding processes are in bold $\left(\geq 10{ }^{\circ} \mathrm{C} \mathrm{s}^{-1}\right)$.

precipitation and surrounded by MA islands, and the second consisting of fine plates with intra-lath carbide precipitation. These are consistent with Widmanstätten ferrite and bainite, respectively. It should be noted, however, that quantification of the fractions of these separate products is not easy using microscopy, and no separate dilatometry signals were observed for them. This is consistent with the results of a previous study of microstructural evolution in SA508 Grade $3^{[23]}$ and with the possibility that the start temperatures of Widmanstätten ferrite and bainite being close in SA508 Grade 3. In steels in which both microconstituents form, Widmanstätten ferrite always forms first owing to the lower driving force required for its formation. ${ }^{[51]} \mathrm{How}-$ ever, when continuously cooling a steel, it is possible that bainite follows Widmanstätten ferrite directly when their start temperatures are close. Since no separate dilatation signals could be found for each constituent, the transformations at intermediate temperatures were treated as both: 'Widmanstätten ferrite/bainite.'

In the FGHAZ samples, a decrease in retained austenite is seen in material cooled at rates of $5{ }^{\circ} \mathrm{C} \mathrm{s}^{-1}$ and above. Figure $8 \mathrm{c}$ shows the microstructure of a FGHAZ sample after cooling at $5{ }^{\circ} \mathrm{C} \mathrm{s}^{-1}$. Again, two similar ferrite morphologies are observed. However, martensite formation in this sample was detected by dilatometry, and this may provide an alternative explanation for the decreased austenite fraction and the fine plate-like formations - it is not trivial to distinguish between autotempered martensite and bainite.

The variation in transformation start temperatures shown in Figure 4 can be explained partially by carbon enrichment of austenite by allotriomorphic/ Widmanstätten ferrite reactions. The suppression of $W_{\mathrm{s}} / B_{\mathrm{s}}$ following allotriomorphic ferrite formation was almost certainly due to carbon parititioning to austenite during allotriomorphic ferrite growth. Austenite can be stabilized both chemically, e.g., through $\mathrm{C}$ enrichment, or mechanically, e.g., by high densities of matrix dislocations inhibiting the displacive transformation. ${ }^{[52-56]}$ However, since allotriomorphic ferrite formation should not lead to deformation of the remaining austenite, a chemical effect is likely to be the only one acting. With regards to the suppression of $M_{\mathrm{s}}$ following Widmanstätten ferrite/bainite formation in the CGHAZ material between 5 and $20{ }^{\circ} \mathrm{C} \mathrm{s}^{-1}$, mechanical stabilization could also be at work. Indeed, the existence of some measure of mechanical stabilization is the only mechanism by which small fractions of austenite could have been retained at the faster cooling rates.

The initial increase in retained austenite with increased cooling rate is perhaps the most unusual result of this study. It is likely that this is result of the time provided for austenite decomposition: for all cooling rates $\leq 2{ }^{\circ} \mathrm{C} \mathrm{s}^{-1}$ there is sufficient time for the carbon enrichment of austenite, but only at the slowest cooling rates is there time for its decomposition on cooling through lower temperatures. Another possible explanation is the increased subdivision and hardening of the austenite by Widmanstätten ferrite formation with increased cooling rate. Subdivision by Widmanstätten plates would have decreased the effective retained austenite grain size, which is well known to suppress $M_{\mathrm{s}}$, e.g., References 57, 58 (some argue this is a geometric effect, ${ }^{[25,59,60]}$ whilst others argue it is due to increased austenite strength and constraint-i.e., mechanical stabilization $\left.{ }^{[55,57,61,62]}\right)$. The displacive Widmanstätten transformation would have led to some austenite deformation, which is known to increase mechanical stabilization too. ${ }^{[52-56]}$ Indeed, the same subdivision and mechanical stabilization arguments can be used to understand the general trend that FGHAZ samples had higher retained austenite fractions than CGHAZ samples for comparable microconstituent fractions. However, what seems contrary to these considerations, is the lower $M_{\mathrm{s}}$ in CGHAZ material than FGHAZ at $100{ }^{\circ} \mathrm{C} \mathrm{s}^{-1}$ cooling rate.

\section{B. Comparison of Modeling and Experiment}

When discussing comparisons of the results from the modeling and experiment, both the hardenability of the steel and the conditions encountered in practical welding scenarios must be taken into consideration in order to 
$\square$ Allotriomorphic Ferrite $\square$ Widmanstatten Ferrite/Bainite $\square$ Martensite $\mathbf{\nabla}$ Austenite

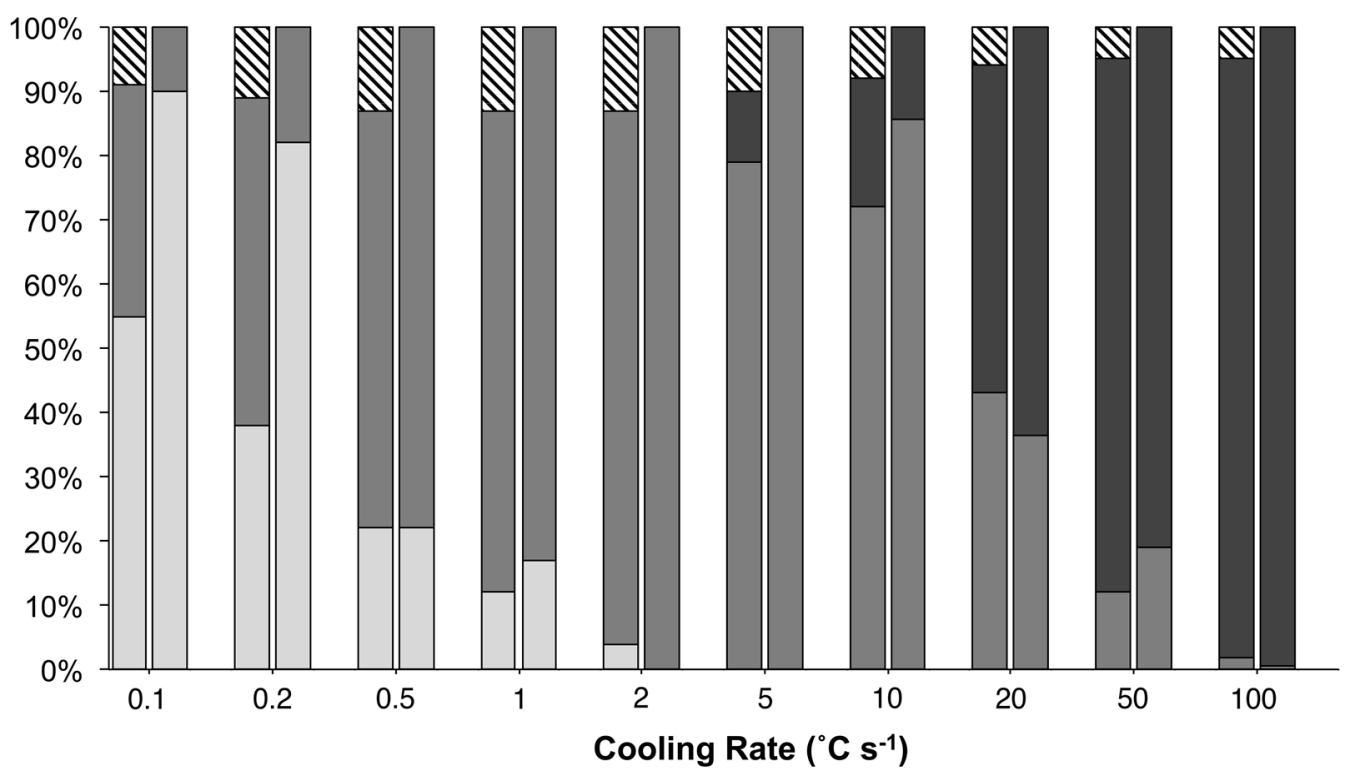

(a)

$\square$ Allotriomorphic Ferrite $\square$ Widmanstatten Ferrite/Bainite $\square$ Martensite $\mathbf{\nabla}$ Austenite

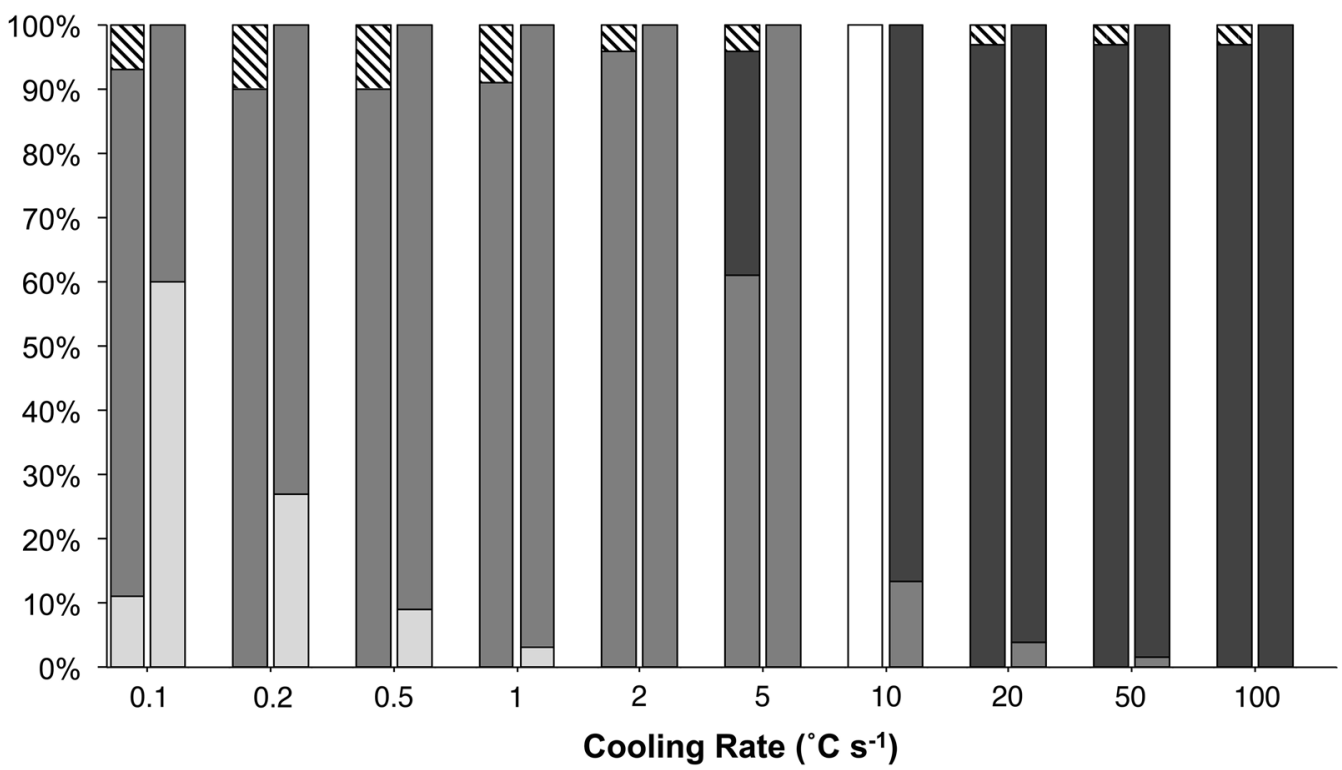

(b)

Fig. 12 - Comparison of microconstituent percentages from experiment (left hand side for each cooling rate) and modeling (right hand side for each cooling rate) for (a) FGHAZ and (b) CGHAZ. For uncertainities in experimental data, see Tables IV and V. No assessment could be made for the CGHAZ with $10{ }^{\circ} \mathrm{C} \mathrm{s}^{-1}$ cooling rate.

judge the significance of any discrepancies. Furthermore, it must be recognized that the evolution of strain with time, and the temperature range over which this occurs, are likely to be the most significant factors driving the development of residual stresses.

For most production welding processes, the cooling rates experienced in the $\mathrm{HAZ}$ are $\geq 10^{\circ} \mathrm{C} \mathrm{s}^{-1}$. At these high cooling rates, the predictions made by the Li et al. model are in good agreement with experimental observations. Even when there was a discrepancy in start temperature (as noted in point (i) in Section IV-B), there was a good match in the evolution of strain. A typical example of this is shown in Figure 13(a) for $20{ }^{\circ} \mathrm{C} \mathrm{s}^{-1}$ in the FGHAZ, in which it is clear that the temperature range in which there is most evolution of strain is well predicted. Start temperature disagreements are associated with temperature ranges over which there is very little transformation. 


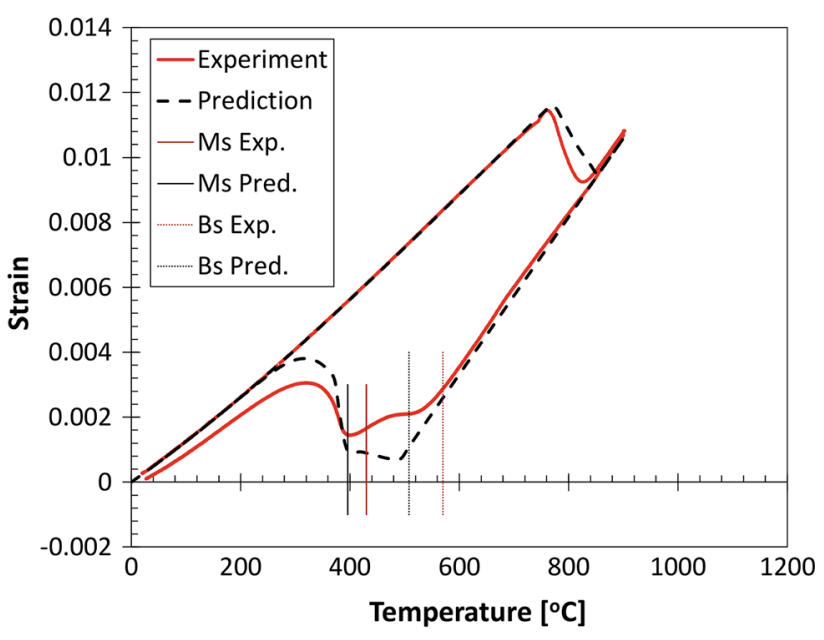

(a)

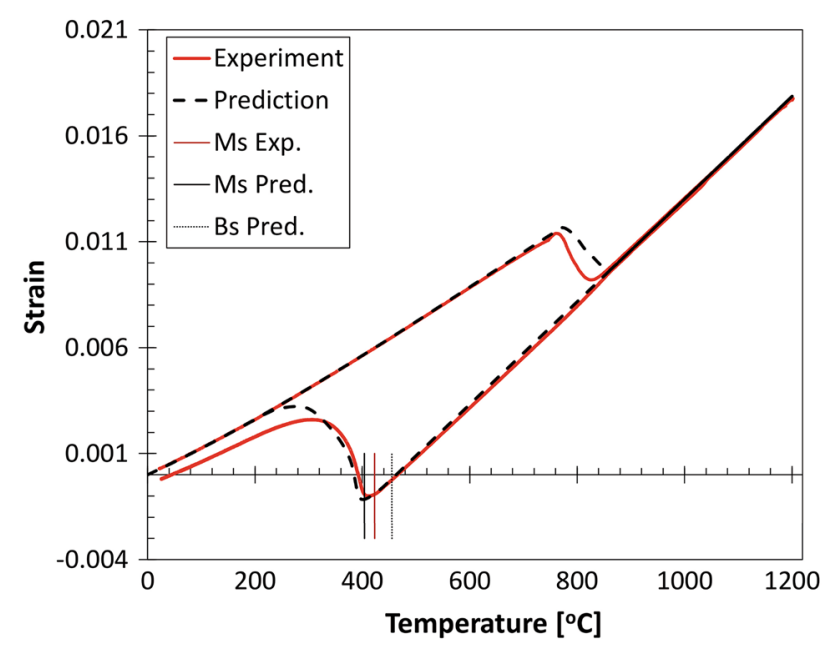

(b)

Fig. 13-Comparison of dilatation curves for modeling and experiment for (a) FGHAZ $20^{\circ} \mathrm{C} \mathrm{s}^{-1}$ and (b) CGHAZ $20{ }^{\circ} \mathrm{C} \mathrm{s}^{-1}$.

The only cases where there were significant differences between modeled and measured dilatation profiles were those for slow-cooled samples (not welding relevant), where the model predicted allotriomorphic ferrite formation at lower temperatures and predicted larger volume fractions (points (ii) and (iii) in Section IV-B). In this work, the predicted growth rates for ferrite were not adjusted to account for the fact that, at all temperatures below the $\mathrm{A}_{3}$ temperature, the equilibrium volume fraction of ferrite in SA508 steel is dependent on temperature. This almost certainly will have contributed to the predictions for the growth rates of ferrite, and hence the final predictions for volume fractions, being too high. Ferrite formation is generally unlikely when austenite in SA508 steel decomposes at cooling rates that are typical of those experienced during welding, so this was not seen as a significant problem when assessing the predictions made by the model in this work. However, it would clearly be of greater importance to make appropriate corrections when applying the model to a steel with a lower hardenability, through using the results of equilibrium calculations performed in ThermoCalc, for instance.

Another discrepancy highlighted in Section IV-B was that the model predicted bainite formation at cooling rates above $10{ }^{\circ} \mathrm{C} \mathrm{s}^{-1}$ in the CGHAZ (point (iv)), but this was not noted experimentally. As highlighted in Section IV-A, this discrepancy is likely to have been a result of being incapable of measuring very small amounts of bainite transformation before martensite start. In other words, there is not a discrepancy when the limitations of the experiment are accounted for. The dilatation curves in such cases matched very well indeed, see Figure 13(b).

On comparison of the full predicted and experimental dilatation curves in Figure 13, it is noted that the model always predicts zero strain as a result of the heat treatment, whilst experimentally the sample always ends shorter than it begins. The likely origins of this could have been the formation of retained austenite, transformation plasticity, and/or experimental issues (e.g., drift during the test). A few pct of retained austenite was always measured experimentally, although the magnitude of the 'shortening' during the experiment did not always match the trend in retained austenite.

Whilst the model was incapable of predicting retained austenite, the presence of the small quantities (3 to $8 \mathrm{pct}$ ) observed in fast-cooled samples are likely to have a limited impact of residual stress generation. Should it be necessary to predict the fraction of retained austenite in the future, the model would have to explicitly for the redistribution of carbon during diffusive (ferrite) or mixed diffusive-displacive (Widmanstätten ferrite) transformations. In addition to predicting retained austenite, this should also in theory allow for the prediction of the suppression of subsequent reactions due to austenite enrichment during allotriomorphic and Widmanstätten ferrite reactions (as is seen in the dilatometry results for the FGHAZ). Implicit in this is that the model is able to predict the formation of Widmanstätten ferrite (that involves carbon partitioning), which is not a feature of the modified Li model used here. This should be included explicitly if the suppression of subsequent martensite and the formation of retained austenite is to be accurately predicted.

Overall, it must be emphasized that, for SA508 Grade 3 steel, the model generally performs well over the cooling rates that are likely to be of practical interest. This augers well for further utilization of the model, since few steels will present a more probing assignment, given that the bainitic nose in the CCT diagram for this steel coincides with typical weld cooling rates. The modifications that have been mentioned above would make only minor improvements to the utility of the model with respect to weld simulation. One might argue that the explicit prediction of Widmanstätten ferrite might change the mechanical response of microstructures under stress, but the yield behavior of microconstituents has a more limited effect on residual stresses than the evolution of transformation strain, which is well predicted (the formation of Widmanstätten ferrite cannot be distinguished from bainite in the dilatation curves). Furthermore, most authors have not made the 
distinction between Widmanstätten ferrite and bainite, and have labelled both features as bainite in spite of evidence of carbon partitioning.

\section{CONCLUSIONS}

1. The phase transformation kinetics in the CGHAZ and FGHAZ of SA508 Grade 3 steel were investigated. As expected, the increased austenite grain size in the CGHAZ led to the expected suppression of transformations to allotriomorphic ferrite, Widmanstätten ferrite and bainite.

2. A decrease in retained austenite and the occurrence of finer lath structures in micrographs suggested a change in the ferrite formation mechanism at intermediate cooling rates from Widmanstätten ferrite (which does partition carbon to form retained austenite) to bainitic ferrite (which does not) as the cooling rate was increased. However, since both transformations occurred in a similar temperature range and did not deliver distinguishable dilatometry signals, their relative fractions could not be assessed. In any case, since no data is available with regards to the particular properties of these microconstituents, the formation of one rather than the other would not influence the results of the model in its current form.

3. Relatively high volume fractions of retained austenite were found at slow cooling rates. The volume fraction was found to increase with increasing cooling rate in this regime, probably due to a decrease in the time provided for decomposition, although austenite subdivision and mechanical stabilization effects could also have played a role. At high cooling rates, the fraction of retained austenite decreased considerably, with mechanical stabilization resulting in just a few percent being present at the highest cooling rates.

4. The results of experiments were compared with predictions made by the model for transformation kinetics presented by Li et al. ${ }^{[31]}$ In general, there was good agreement between the measured and predicted transformation start temperatures, apart from for the Widmanstätten ferrite/bainite start temperature for the FGHAZ and for the allotriomorphic ferrite start temperature for the CGHAZ. The model also failed to predict the formation of Widmanstätten ferrite/bainite at the slowest cooling rates for the FGHAZ. Nevertheless, for the cooling rates applicable to practical welding processes the model performed well, and the overall development of transformation strains as a function of temperature were well predicted by the model for fast cooling even when there was a disagreement in transformation start temperatures. This would suggest the model can be used relatively effectively in residual stress simulations that account for solid-state reaction kinetics.

5. In future, the model could be changed to more accurately predict transformation behaviors at the slowest cooling rates. In particular, the model could be improved by it accounting for the effects of carbon redistribution during allotriomorphic/Widmanstätten ferrite formation. This redistribution controls the rate at which allotriomorphic ferrite grows, the suppression of subsequent austenite transformations, and the formation of retained austenite.

\section{ACKNOWLEDGMENTS}

This work was funded as part of the Engineering and Physical Sciences Research Council (EPSRC) NNUMAN Programme: EP/J021172/1. Professor M.C. Smith is funded by an EPSRC Manufacturing Fellowship: EP/L015013/1. Professor M. Preuss is funded by an EPSRC Leadership Fellowship: EP/ I005420/1. The NanoSIMS was funded by UK Research Partnership Investment Funding (UKRPIF) Manchester RPIF Round 2. The authors would like to thank G. McMahon for his assistance in carrying out the NanoSIMS experiments, and Dr. Cory Hamelin, Dr. Philip Bendeich and Professor M.V. Li for the discussions on the metallurgical model. The raw dilatometry and synchrotron X-ray diffraction data for this work can be found here: DOI 10.5281/zenodo.1283899.

\section{OPEN ACCESS}

This article is distributed under the terms of the Creative Commons Attribution 4.0 International License (http://creativecommons.org/licenses/by/4.0/), which permits unrestricted use, distribution, and reproduction in any medium, provided you give appropriate credit to the original author(s) and the source, provide a link to the Creative Commons license, and indicate if changes were made.

\section{REFERENCES}

1. D.P.G. Lidbury: Int. J. Press Vessel. Pip., 1984, vol. 17, pp. 197-328.

2. D.T. Read: Eng. Fract. Mech., 1989, vol. 32, pp. 147-53.

3. X. Cheng, J.W. Fisher, H.J. Prask, T. Gnaupel-Herold, B.T. Yen, and S. Roy: Int. J. Fatigue., 2003, vol. 25, pp. 1259-69.

4. W. Fricke: Mater. Werkstofftechn., 2005, vol. 36, pp. 642-64.

5. M. Turski, A.H. Sherry, P.J. Bouchard, and P.J. Withers: $J$. Neutron Res., 2004, vol. 12, pp. 45-49.

6. P.J. Bouchard, P.J. Withers, S.A. McDonald, and R.K. Heenan: Acta Mater., 2004, vol. 52, pp. 23-34

7. D.J. Hornbach and P.S. Prevey: J. Press. Technol., 2002, vol. 124, pp. $359-65$.

8. S. Sjöström: Mater. Sci. Technol., 1985, vol. 1, pp. 823-29.

9. J.A. Francis, H.K.D.H. Bhadeshia, and P.J. Withers: Mater. Sci. Technol., 2007, vol. 23, pp. 1009-20.

10. C.J. Hamelin, O. Muránsky, M.C. Smith, T.M. Holden, V. Luzin, P.J. Bendeich, and L. Edwards: Acta Mater., 2014, vol. 75, pp. $1-19$.

11. G.W. Greenwood and R.H. Johnson: Proc. R. Soc., 1965, vol. 283, pp. 403-22.

12. G. Wassermann: Arch. Eisenhuettenw., 1937, vol. 10, pp. 321-25. 
13. C.L. Magee, H.W. Paxton, Ph.D. Thesis, 1966, Carnegie Inst. Technol., Pittburgh, PA.

14. Y.E. Majaty, J.-B. Leblond, and D. Kondo: J. Mech. Phys. Solids., 2018, vol. 121, pp. 175-97.

15. D. Weisz-Patrault: J. Mech. Phys. Solids., 2017, vol. 106, pp. $152-75$

16. J.B. Leblond, G. Mottet, and J.C. Devaux: J. Mech. Phys. Solids., 1984, vol. 34, pp. 411-32.

17. J.-B. Leblond, G. Mottet, and J. Devaux: J. Mech. Phys. Solids., 1986, vol. 34, pp. 395-409.

18. D.F. Watt, L. Coon, M. Bibby, J. Goldak, and C. Henwood: Acta Metall., 1988, vol. 36, pp. 3029-35.

19. H. Dai, J.A. Francis, and P.J. Withers: Mater. Sci. Technol., 2013, vol. 26 , pp. $940-49$.

20. H. Dai, J.A. Francis, H.J. Stone, H.K.D.H. Bhadeshia, and P.J. Withers: Metall. Mater. Trans. A., 2008, vol. 39A, pp. 3070-78.

21. ASTM: Standard Specification for Quenched and Tempered Vacuum- Treated Carbon and Alloy Steel Forgings for Pressure Vessels 1, Test. 01, 1999, 1-6.

22. Y.K. Suzuki, I. Kurihara, T. Sasaki, and Y. Koyoma: Tanaka: Nucl. Eng. Des., 2001, vol. 206, pp. 261-78.

23. E.J. Pickering and H.K.D.H. Bhadehia: Metall. Mater. Trans. A., 2014, vol. 45A, pp. 2983-97.

24. E.J. Pickering, C. Chesma, S. Al-Bermani, M. Holland, P. Davies, and J. Talamantes-Silva: Metall. Mater. Trans. B., 2015, vol. 46B, pp. 1860-74.

25. H. Yang and H.K.D.H. Bhadeshia: Mater. Sci. Technol., 2007, vol. 23 , pp. $556-60$.

26. M. Onink, C.M. Brakman, F.D. Tichelaar, E.J. Mittemeijer, S. van der Zwaag, J.H. Root, and N.B. Konyer: Scr. Metall. Mater., 1993, vol. 29, pp. 1011-16.

27. A. Hammersley: Fit2D software package, 1998, ESRF, http://w ww.esrf.eu/computing/scientific/FIT2D/.

28. Bruker AXS GmbH: TOPAS software package, version 4.2, 2009.

29. F. Bachmann, R. Hielscher, and H. Schaeben: Solid State Phenom., 2010, vol. 160, pp. 63-68.

30. L.R.R. Nitter: L'Image software package, http://Limagesoftware. Net., 1997.

31. M.V. Li, D.V. Niebuhr, L.L. Meekisho, and D.G. Atteridge: Metall. Mater. Trans. B, 1998, vol. 29B, pp. 661-72.

32. A.N. Vasileiou, M.C. Smith, J. Balakrishnan, J.A. Francis, and C.J. Hamelin: Nucl. Eng. Des., 2017, vol. 323, pp. 309-16.

33. D. Venugopalan, J.S. Kirkaldy: Phase Transformations in Ferrous Alloys, eds. A.R. Marder and J.I. Goldstein, 1984, New York, AIME.

34. Thermo-Calc software package, version 2017a, TCFE8 database, 2017.
35. RA Grange: Metal Prog., 1961, vol. 79, pp. 73-75.

36. K.W. Andrews: J. Iron Steel Inst., 1965, 721-27.

37. J. Barralis and G. Maeder: Metallurgie [Tome I, Metallurgie Phys], 1982, Collect. Sci. ENSAM.

38. N.O. Meara, H. Abdolvand, J.A. Francis, S.D. Smith, and P.J. Withers: Mater. Sci. Technol., 2016, vol. 32, pp. 1517-32.

39. S. Erich: Zeitschrift Für Metallk, 1942, vol. 34, pp. 70-72.

40. M. Avrami: J. Chem. Phys., 1941, vol. 9, pp. 177-84.

41. M. Avrami: J. Chem. Phys., 1940, vol. 8, pp. 212-24.

42. M. Avrami: J. Chem. Phys., 1939, vol. 7, pp. 1103-12.

43. C.Y. Kung and J.J. Rayment: Metall. Trans. A., 1982, vol. 13, pp. 328-31.

44. D.P. Koistinen and R.E. Marburger: Acta Metall., 1959, vol. 7, pp. 59-60.

45. Daussault Systems, Inc. 2013. "SIMULIA. ABAQUS/Standard, Daussault Syst. Inc. (2013).

46. J. Bouchard, M.C. Smith, and S.K. Bate: ASME 2013 Press. Vessel. Pip. Conf., 2013, Paris, France.

47. S.K. Bate:, Protocol for finite element simulations of an autogenous welded beam specimen, Serco Gr. Plc, 2010.

48. H. Pous-romero, I. Lonardelli, D. Cogswell, and H.K.D.H. Bhadeshia: Mater. Sci. Eng. A., 2013, vol. 567, pp. 72-79.

49. H.K.D.H. Bhadeshia: Metall. Trans. A., 1979, vol. 10, pp. 895-907.

50. E. Kozeschnik and H.K.D.H. Bhadeshia: Mater. Sci. Technol., 2008, vol. 24, pp. 343-47.

51. H.K.D.H. Bhadeshia, Bainite in steels: theory and practice, 3rd ed., 2015, Maney, Leeds, UK.

52. C. Morris and E.S. Machlin: Trans. Met. Soc. AIME., 1951, vol. 191, pp. 746-54.

53. E.M. Breinan and G.S. Ansel: Metall. Trans., 1970, vol. 1, pp. 1513-20.

54. J.R. Strife, M.J. Carr, and G.S. Ansell: Metall. Trans. A., 1977, vol. 8, pp. 1471-84.

55. S. Kajiwara: Metall. Mater. Trans. A, 1986, vol. 17A, pp. 1693-1702.

56. S.M.C. van Bohemen and J Sietsma: Mater. Sci. Eng. A., 2010, vol. 527, pp. 6672-76.

57. P.J. Brofman and G.S. Ansell: Metall. Trans. A., 1983, vol. 14A, pp. 1929-31.

58. S. Lee and Y. Lee: Mater. Sci. Forum., 2005, vol. 479, pp. 3169-72.

59. D. Turnbull, J.C. Fisher, and J.H. Hollomon: Met. Trans., 1949, vol. 185 , pp. $691-700$.

60. W.C. Leslie and R.L. Miller: ASM Trans., 1964, vol. 57, pp. $972-79$.

61. J.R.C. Guimaraes: Scripta Mater., 2007, vol. 57, pp. 237-39.

62. J. Hidalgo and M.J. Santofimia: Metall. Mater. Trans. A., 2016, vol. 47, pp. 5288-5301. 